\title{
Three Retirement Decision Models for Defined Contribution Pension Plan Members: A Simulation Study
}

\author{
Bonnie-Jeanne MacDonald* Andrew J.G. Cairns ${ }^{\dagger}$
}

\begin{abstract}
This paper examines the hypothetical retirement behavior of defined contribution (DC) pension plan participants. Using a Monte Carlo simulation approach, we compare and discuss three retirement decision models: the two-thirds replacement ratio benchmark model, the optionvalue of continued work model and a newly-developed "one-year" retirement decision model. Unlike defined benefit (DB) pension plans where economic incentives create spikes in retirement at particular ages, all three retirement decision models suggest that the retirement ages of DC participants are much more smoothly distributed over a wide range of ages. We find that the one-year model possesses several advantages over the other two models when representing the theoretical retirement choice of a DC pension plan participant. First, its underlying theory for retirement decision-making is more feasible given the distinct features and pension drivers of a DC plan. Second, its specifications produce a more logical relationship between an individual's decision to retire and his/her age and accumulated retirement wealth. Lastly, although the one-year model is less complex than the option-value model as the DC participants' scope is only one year, the retirement decision is optimal over all future projected years if projections are made using reasonable financial assumptions.
\end{abstract}

Keywords: defined contribution pension plan; dynamic and stochastic simulation; one-year retirement decision model; two-thirds model; option-value of continued work model.

JEL: G11, J26, J33.

\footnotetext{
${ }^{*}$ Corresponding Author. Department of Economics, Dalhousie University, Halifax, Nova Scotia, Canada, B3P 1A9. Tel: + 902 471-6660. E-mail address: BonnieJeanne_MacDonald@hotmail.com

${ }^{\dagger}$ Maxwell Institute for Mathematical Sciences, Edinburgh, and Department of Actuarial Mathematics and Statistics, School of Mathematical and Computer Sciences, Heriot-Watt University, Edinburgh, U.K., EH14 4AS
} 


\section{Introduction}

It is widely known that defined contribution (DC) pension plans are on the rise around the world in the private pension plan domain as well as in state pension systems, in both developed and nondeveloped countries ${ }^{1}$. As DC pension plans emerge, more consideration should be given to the consequential effect on retirement behavior patterns. Defined benefit (DB) pension plans have historically dominated the pension plan world and past published research has focused almost exclusively on the retirement behavior of DB plan participants while saying very little on the retirement conduct of DC plan participants. For instance, numerous studies have investigated the influence of DB pension plan benefits on retirement behavior using the popular "option-value of continued work" retirement decision model (Stock and Wise, 1990a), including Stock and Wise (1990a, 1990b), Lumsdaine et al. (1990, 1992, 1994), Samwick (1998a), Hakola (1999), Coile and Gruber (2000), Harris (2001), Samwick and Wise (2001), Hurd et al. (2003), Piekkola and Deschryvere (2004), Gruber and Wise (2004), and Asch et al. (2005). A central feature in the development of the option-value model was to capture the influence of pension benefit incentives on the retirement decision. It has been predominantly used to model the retirement behavior of DB participants since important incentives are present in the DB pension accrual pattern. For instance, this decision model takes account of DB plan rules concerning early and sometimes late retirement.

Our goal is to investigate the less familiar retirement decision-making process of a worker with a DC pension plan. Retirement decision models found to be helpful in capturing the retirement behavior of DB plan members may or may not be be suitable in describing a DC member's approach to retirement. Recent empirical studies have suggested that the rules governing retirement behavior under a DB pension plan do not match those under a DC pension plan. Friedberg and Webb (2000) reported that they have found substantial changes in the retirement patterns among US workers, to which they attributed to the spread of DC type plans in the US.

This paper explores three hypothetical approaches taken among DC plan participants in their decision to retire. We first examine the two-thirds retirement decision model, where workers retire once their accumulated pension fund can replace two-thirds of their earnings. This model can be criticized as not being "forward looking" since potential increments in future pension and employment income do not affect the retirement decision. We next consider the option-value of continued work model (Stock and Wise, 1990a), which takes into consideration all future retirement opportunities in the retirement decision. The option-value model is a well developed and researched model that has been discussed and applied by numerous authors as noted above. Finally, we present the one-year (OY) retirement decision model. The two features that distinguish the OY model from the option-value model are (1) the OY model approaches the retirement decision by regarding only the added value of delaying retirement by one year rather than all future retirement possibilities, and (2) there is a second leisure component in the OY model.

This study builds on the stochastic simulation model developed in MacDonald and Cairns (2007), which is summarized in Section 2. Section 3 follows, describing each retirement decision model ${ }^{2}$. Section 4 explores the theoretical retirement behavior of DC pension plan members.

\footnotetext{
${ }^{1}$ See Broadbent, Palumbo and Woodman (2006) for a description and discussion of the worldwide shift towards DC pension plans.

${ }^{2}$ The appendices provide further details on the retirement decision models. Appendix A discusses our parameter estimates and Appendix B details the execution of the retirement decision models by explaining how members form expectations of future income.
} 
Section 5 presents the simulated results. Section 6 investigates the optimality of the retirement choice generated by the OY model. Section 7 examines the implied relationship between an individual's choice to retire and his/her current pension and age under each retirement decision model. This section also tests the sensitivity of the utility function parameter estimates. Section 8 gives a few suggestions for future work and, finally, Section 9 summarizes the primary findings.

The conclusions reached in this paper are theoretical - they are based on a qualitative examination of the three models (Section 4) and the simulated retirement behavior generated by each (Sections 5, 6 and 7). In future work, we hope to ascertain which of the models best describes the retirement behavior of DC participants by testing each model against empirical data.

\section{Model and Assumptions}

This study stochastically simulates the retirement decision behavior of DC participants. To do so, we simulate the worker's financial career path, savings accumulation and choice to retire using the approach outlined in MacDonald and Cairns (2007), except we now include two additional retirement decision models. The following is a brief bullet point summary of the assumptions:

- All private and public sources of retirement income are treated as a single DC pension plan.

- The DC pension plan is a pure design in the sense that we do not include any government/employer imposed restrictions. For instance, there exists neither a minimum pension guarantee, a minimum period of enrollment for vesting, nor a mandatory retirement age.

- Five assets are available for investment: equities, fixed-income bonds, index-linked bonds, risk-free one-year bonds (cash) and index-linked cash.

- There are 581 available portfolio strategies, each containing a different combination of the five assets. We test the portfolio's exposure to bonds, index-linked bonds and equities in increments of $10 \%$ of the total portfolio. We examine only $20 \%$ increments for cash and index-linked cash since they play a minor role in the outcome (Section 5 finds that they are not optimal investment choices).

- The Vasicek interest rate model (Vasicek, 1977) underpins the dynamics of the economic variables.

- The relationship among the annuitization rates, financial market rates of return and earnings growth are modeled from year to year.

- The participant's earnings model is composed of the prevailing level of inflation and real wage growth, which are both stochastic. It also includes a merit scale that is a deterministic function of years of employment.

- A participant begins working at age 20 , enters the DC pension plan at age 25 , has no dependents, makes an annual $10 \%$ of earnings contribution to his/her retirement account and chooses a static asset allocation strategy. A short examination of the effect of varying these assumptions was done in MacDonald and Cairns (2007). 
- We assume neither taxes, expenses, nor allowances for profit in the financial assets' pricing, the management of the DC plan, nor the cost of purchasing annuities.

- We rely on fixed income annuities as the funding medium benchmark to calculate the pension benefit income available from the accumulated DC funds.

- The annual mortality rate is a fixed blend of $50 \%$ of the male mortality rate and $50 \%$ of the female mortality rate in the 2002 United States Life Tables (Arias, 2004).

- We assume that retirement patterns, asset demand and labour force participation rates do not affect the market equilibrium asset returns or the wage earnings, although in reality we would expect some feedback ${ }^{3}$.

- We consider retirement an absorbing state and a retired member cannot reenter the workforce.

MacDonald and Cairns (2007) explained the rationale behind our assumptions.

Our modeling is not country-specific and it does not include any country's labour laws or tax and transfer system. Including the contemporary complexities of regulations and tax incentives for any particular country at this stage would convolute the analysis since the results would be blurred by the country's public policy rather than the effect of using alternative retirement decision models .

Unfortunately, owing to its complexity, even existing published research of a more practical nature nearly universally ignores labour laws, taxes and government transfers when analyzing the value of income generated from DC style accounts ${ }^{5}$. Moreover, as far as we can find, previously published work employing the option-value model has neglected the important role played by the country's tax and transfer system by inputting wage earnings and retirement benefits before tax.

\section{Retirement Decision Models}

This section outlines the two-thirds, option-value and OY retirement decision models.

\subsection{Two-thirds Retirement Model}

The two-thirds model, described in MacDonald and Cairns (2007), states that a DC member retires once his/her DC account can replace two-thirds of his/her current earnings.

We calculate the pension purchasable by dividing the accumulated pension wealth, $P W(t)$, by a life annuity factor, $\ddot{a}_{x}(t)$. The pension income divided by the individual's preretirement earnings is referred to as the replacement ratio, $R R(t)$ :

$$
R R(t)=\frac{P W(t) / \ddot{a}_{x}(t)}{Y(t)}
$$

where

\footnotetext{
${ }^{3}$ MacDonald and Cairns (2009) studied the potential impact of feedback among these variables.

${ }^{4}$ For example, if a country promoted retirement at a particular age by giving preferential tax treatment to retirement income over wage income, then this tax wedge would generate results skewed to that age for all of the retirement decision models. Additions of this sort would increasingly create difficulties in distinguishing public policy incentives from the retirement decision behavior implied by the features of the models.

${ }^{5}$ Samples of this line of research include Blake et al. (2003); Dus et al. (2004); Horneff et al. (2007), and Milevsky and Young (2007).
} 
$t$ : current time;

$x$ : member's current age at time $t$;

$\ddot{a}_{x}(t)$ : the annuity factor at time $t$ for an individual aged $x$ (see Appendix B for formula);

$P W(t)$ : the worker's accumulated DC pension wealth at time $t$; and

$Y(t)$ : the worker's earnings at time $t$.

The plan member retires as soon as the replacement ratio exceeds two-thirds; that is:

$$
\text { Retirement Age }=\min \left\{x: \quad R R(t) \geq \frac{2}{3}\right\} .
$$

The two-thirds benchmark is an adequate earnings replacement level according to the range given in a report prepared by the Canadian Institute of Actuaries (1996). It is also near the actual average replacement ratio, measured from all sources of retirement income, in each of the OECD countries (Disney, d'Ercole and Scherer, 1998) (see MacDonald and Cairns (2007) for a further discussion on the two-thirds target).

The two-thirds model implies that the retirement decision is directly responsive to wealth shocks. Sevak (2002) showed that workers in the 1990s reacted to the positive wealth shocks by retiring earlier. Arriving at the same conclusion, Coronado and Perozek (2001) also proposed that the likely cause of the delay in retirement among workers following the 1990s was the poor equity performance.

Age enters indirectly into the retirement decision since the annuity factor becomes cheaper with age owing to the increasingly higher mortality premium in the annuity's pricing.

\subsection{Option-value Retirement Decision Model}

The option-value model, developed in Stock and Wise (1990a, 1990b), stipulated that at the beginning of each year the individual chooses to retire or to continue working based on the potential value he/she expects to derive under each option. It assumes that a worker intuitively compares the value of immediate retirement with the maximum expected value of retiring at all future ages. Retirement is delayed if the latter value exceeds the former. When considering the value of continued employment, the workers take into account both the income they could earn from future employment and the extra pension wealth they could accumulate. This is weighed against the value of immediate retirement, bringing with it the lure of leisure together with a pension funded by their DC account.

The option-value model is among the structural retirement decision models that began to surface in the $1980 s^{6}$. These models are characterized as employing utility functions to optimize the retirement decision over the entire lifetime consumption of the worker (Hurd et al., 2003). Stock and Wise (1990a) discussed the benefits of the option-value model over the existing approaches that had been used to analyze retirement behavior. They explained that embedded in some retirement decision models is the assumption that individuals know with confidence their future finances, such as wage earnings, at the time of calculation and that the information is not updated with the emergence of actual experience. Furthermore, they criticized the lack of "forward looking" features in

\footnotetext{
${ }^{6} \mathrm{~A}$ helpful report that was released after the writing of this paper was Belloni (2008). It provided a historical review of retirement decision modeling, with a particular focus on the option-value model.
} 
models that do not allow increments in future pensions to affect the decision to retire. The optionvalue model overcomes these drawbacks as it is both dynamic and "forward-looking". In addition, not only is the option-value model convenient to estimate (Burkhauser et al., 2003), several papers concluded that the option-value model performs equally well, if not better, in explaining and predicting the behavior of individuals than the more computationally complex alternatives, such as the dynamic programming model (Lumsdaine et al., 1990; Burkhauser et al., 2003). The primary measure of predictive validity was the ability of the model to accurately predict the actual behavior effect brought about by policy changes. Comparisons were also made with simpler models, such as the reduced form hazard model (Burkhauser et al., 2003) and several probit models for different determinants of retirement (Lumsdaine et al., 1990), all of which were outperformed by the optionvalue model. Furthermore, Samwick (1998a) showed that the calculated option-value of continued work performed better as a predictor of retirement in a probit equation than simple one-year retirement accruals. Coile and Gruber (2000) similarly concluded that workers are affected far more by the pension incentives available over their entire lives, measured by the option-value, than the basic coming year pension accrual, by also comparing their effects as a variable in a probit model.

For the most part, the option-value model has been used to study the effects of DB pension plan provisions on the retirement choice, whether it be specific large firm pension plans (Stock and Wise, 1990a; Lumsdaine et al., 1990, 1992; Asch et al., 2005) and/or aspects of US Social Security (Stock and Wise, 1990b; Lumsdaine et al., 1994; Samwick, 1998a; Hakola, 1999; Coile and Gruber, 2000; Harris, 2001; Samwick and Wise, 2001; Gruber and Wise, 2004; Hurd et al., 2003; Piekkola and Deschryvere, 2004). Although its application has been predominantly within a DB plan framework, it has also been used to model the behavior of DC participants. For example, Stock and Wise (1990a) and Lumsdaine et al. (1994) simulated the retirement behavior of individuals under a DC plan using the option-value model to analyze the behavioral consequences of switching to this plan design. Its application, by the primary developers of the model, to describe the retirement behavior of DC participants justifies its relevance in our study.

In summary, key assumptions in the option-value model include:

- A participant re-evaluates his/her retirement decision every year as new information becomes available.

- A participant considers all future pension possibilities when contemplating retirement.

- In the context of a DC plan, the factors influencing the decision to retire are the worker's level of wealth, desire for leisure, current earnings, risk aversion with regard to income stability, personal discount factor, the price to annuitize and economic projection assumptions.

The option-value model, described fully in Stock and Wise (1990a), is explained briefly here. When determining whether to retire at time $R$, the worker weighs the utility of future income using the discounted utility value function:

$$
V^{R}(t)=\sum_{s=t}^{R-1} \beta^{s-t}{ }_{s-t} \mathrm{p}_{x} U_{w}\left(\frac{C(s)}{Y(t)}\right)+\sum_{s=R}^{\infty} \beta^{s-t}{ }_{s-t} \mathrm{p}_{x} U_{r}\left(\frac{C^{R}(s)}{Y(t)}\right)
$$

where $\sum_{s=t}^{R-1}()=$.0 if $R=t,{ }_{s-t} \mathrm{p}_{x}$ is the probability of survival in the next $s-t$ years for someone aged $x$, and:

$V^{R}(t)$ : discounted utility value function at time $t$ conditional on retirement at time $R$; 
$t$ : current time;

$R$ : time of retirement;

$\beta$ : personal discount factor (fixed parameter);

$C(s)$ : consumption at time $s$ while working $(=(1-\pi) Y(s))$;

$C^{R}(s)$ : pension consumption at time $s$ conditional on retirement at time $R\left(=P W(R) / \ddot{a}_{x+R-t}(R)\right)$;

$U_{w}(c)$ : utility function of working consumption; and

$U_{r}(c)$ : utility function of retirement consumption.

To simulate the option-value model, we divide current consumption by current earnings, $Y(t)$, to compensate for the corrosive effect of earnings inflation on the disturbance terms, $\omega(s)$ and $\xi(s)$, in Eqs. (3) and (4) below. For this reason, the utilities measured from time $t$ are functions of $C^{R}(s) / Y(t)$ and $C(s) / Y(t)$ rather than $C^{R}(s)$ and $C(s) . Y(t)$ is, however, an exogenous constraint in the maximization of utility. This adjustment was not necessary in past published research employing the option-value model since, for instance, the majority of authors, including Stock and Wise (1990b), estimated the option-value model with a single year's data and considered only the retirement probability in a single year. In our study, however, we simulate the retirement decision in every year of the worker's career, making this type of adjustment necessary.

The first term on the right-hand side of Eq. (2) is the discounted utility of future working income net of pension contributions, and the second term is the discounted utility of future pension benefits after retirement.

Stock and Wise (1990a) parameterized the utility functions of wage and retirement income at time $t$ as:

$$
U_{w}\left(\frac{C(s)}{Y(t)}\right)=\left(\frac{C(s)}{Y(t)}\right)^{\gamma}+\omega(s)
$$

and

$$
U_{r}\left(\frac{C^{R}(s)}{Y(t)}\right)=\left(k \times \frac{C^{R}(s)}{Y(t)}\right)^{\gamma}+\xi(s)
$$

where:

$k$ : relative value of income during retirement (fixed parameter) arising from the increased utility from leisure after retirement $(\mathrm{k} \geq 1)$; and

$\gamma$ : risk aversion (fixed parameter).

The utility derived from annual income is the sum of a power utility function? (with a multiplicative leisure component during retirement), and a disturbance term distributed independently of income and age. The disturbance terms, $\omega(s)$ and $\xi(s)$, are individual-specific random effects such as individual preference for work versus leisure or evolving health status. Stock and Wise (1990a) assumed the disturbance terms follow a Markovian (first order autoregressive) process:

$$
\omega(s)=\rho \omega(s-1)+\varepsilon_{\omega}(s), E_{s-1}\left(\varepsilon_{\omega}(s)\right)=0,
$$

\footnotetext{
${ }^{7}$ Merton (1969) explained the benefits of using the power utility function and constant, non-negative time preference.
} 


$$
\xi(s)=\rho \xi(s-1)+\varepsilon_{\xi}(s), E_{s-1}\left(\varepsilon_{\xi}(s)\right)=0 .
$$

The option-value of postponing retirement equals:

- the maximum of the expected discounted utility values of retiring at each future age

\section{- minus}

- the expected discounted utility value of immediate retirement.

Combining the above equations, therefore, the option-value of continued work is defined as $E_{t}\left(V^{R^{*}}(t)\right)-$ $E_{t}\left(V^{t}(t)\right)$, where $E_{t}($.$) represents the individual's expectation about the future given the information$ at time $t$ and $R^{*}$ is the retirement time $(>t)$ that maximizes over all future retirement dates. We replace the full expectation $\left(E_{t}().\right)$ with the individual's "best estimate" in Appendix B for purposes of practicality and realism.

To measure the option-value of continued work, the following is calculated for every future year $R$ to determine its maximum.

$$
\begin{aligned}
& E_{t}\left(V^{R}(t)\right)-E_{t}\left(V^{t}(t)\right) \\
= & \sum_{s=t}^{R-1} \beta^{s-t}{ }_{s-t} \mathrm{p}_{x} E_{t}\left(\left(\frac{C(s)}{Y(t)}\right)^{\gamma}+\omega(s)\right) \\
& +\sum_{s=R}^{\infty} \beta^{s-t}{ }_{s-t} \mathrm{p}_{x} E_{t}\left(k^{\gamma} \times\left(\frac{C^{R}(s)}{Y(t)}\right)^{\gamma}+\xi(s)\right) \\
& -\sum_{s=t}^{\infty} \beta^{s-t}{ }_{s-t} \mathrm{p}_{x}\left[k^{\gamma} \times\left(\frac{C^{t}(s)}{Y(t)}\right)^{\gamma}+E_{t}(\xi(s))\right] \\
= & \sum_{s=t}^{R-1}\left(\frac{\beta^{s-t}{ }_{s-t} \mathrm{p}_{x}}{Y(t)^{\gamma}}\right) E_{t}\left(C(s)^{\gamma}\right)+\sum_{s=R}^{\infty} \beta^{s-t}{ }_{s-t} \mathrm{p}_{x}\left(\frac{k}{Y(t)}\right)^{\gamma} E_{t}\left(C^{R}(R)^{\gamma}\right) \\
& -\sum_{s=t}^{\infty} \beta^{s-t}{ }_{s-t} \mathrm{p}_{x}\left(\frac{k C^{t}(t)}{Y(t)}\right)^{\gamma}+\sum_{s=t}^{R-1} \beta^{s-t}{ }_{s-t} \mathrm{p}_{x} E_{t}(\omega(s)-\xi(s)) .
\end{aligned}
$$

Retirement occurs if $E_{t}\left(V^{t}(t)\right) \geq E_{t}\left(V^{R}(t)\right)$ for all $R>t$, meaning that the option-value of continued work, $E_{t}\left(V^{R^{*}}(t)\right)-E_{t}\left(V^{t}(t)\right)$, is negative and there is no utility value expected to be gained from continuing to work.

In Eq. (7), $E_{t}($.$) is dropped for C^{t}(t)$ and $C(t)$ since they are observable at time $t\left(C(s)=C^{t}(t)=\right.$ $P W(t) / \ddot{a}_{x}(t)$ for $s \geq t$ and $\left.C(t)=(1-\pi) Y(t)\right)$.

The model assumes that the individual knows $\omega(s)$ and $\xi(s)$ only at time $s$ and not before. In Eq. (7), a participant forecasts future values of $\omega(s)$ and $\xi(s)$ using Eqs. (5) and (6), which reflects the anticipated persistence of individual circumstances over time based on the current information. The expectations of $\varepsilon_{\omega}(s)$ and $\varepsilon_{\xi}(s)$ are both zero in Eqs. (5) and (6); letting $v(s)=\omega(s)-\xi(s)$, therefore, the disturbance term component of Eq. (7) is reduced to:

$$
\sum_{s=t}^{R-1} \beta^{s-t}{ }_{s-t} \mathrm{p}_{x} E_{t}(v(s))=\sum_{s=t}^{R-1} \beta^{s-t}{ }_{s-t} \mathrm{p}_{x} \rho^{s-t} v(t)
$$


which is only dependent on the disturbance term at time $t$ since the expected value of $v(s)$ is $\rho^{s-t} v(t)$ for all future years $s$. In Eq. (8), the further $R$ is into the future, the larger the disturbance term component becomes since there are more years in the summation. In a given year, therefore, an older employee will have less uncertainty surrounding the value that he/she places on retirement at age $x+R-t$ relative to a younger employee who considers the same retirement age. This is reasonable seeing that greater uncertainty should accompany longer planning horizons.

Stock and Wise (1990a) set the random terms in Eqs. (5) and (6) to follow a random walk with $\rho=1$ :

$$
v(s)=v(s-1)+\varepsilon(s), \varepsilon(s) \text { is i.i.d } \sim N\left(0, \sigma_{\varepsilon}^{2}\right),
$$

where the initial value, $v(t)$, is i.i.d $\sim \mathrm{N}\left(0, \sigma_{v}^{2}\right)$ and independent of $\varepsilon(s), s \geq t+1$. In our stochastic model, we simulate $v(t)$ with $\sigma_{v} Z(t)$ in the worker's year of entry, where $Z(t)$ denotes independent standard normal random variables (i.i.d. $\sim \mathrm{N}(0,1)$ ). In each consecutive year of simulation following the year of entry, we generate $\varepsilon(s)$ using $\sigma_{\varepsilon} Z(s)$.

The two-thirds model assumes that the worker gives no weight to future retirement opportunities but retires as soon as he/she is satisfied with his/her accumulated wealth. If we remove the forward-looking feature and the random component in the option-value model, then it too would behave in this way. The option-value model states that the ratio of the utility of retirement to the utility of employment is $\left(k C^{R}(s) / C(s)\right)^{\gamma}$ at any given age $s$ (Stock and Wise, 1990a). If the worker had no regard for the future and only considered utility in the current year then, according to our assumptions, retirement would occur if the earnings replacement ratio was sufficiently large. This is identical to the two-thirds model except the target replacement ratio is $(1-\pi) / k$ as opposed to two-thirds.

\subsection{One-Year Retirement Model}

The primary difference between the OY model and the option-value model is in the forward-looking feature. The option-value model assumes that workers consider all future retirement opportunities over their remaining lifetime before deciding to retire. On the other hand, the OY model assumes that workers only consider the added benefit of working a single additional year. More short-sighted still is the two-thirds model, which has no concern for future pension possibilities.

We express the OY model using the option-value notation that appeared in Section 3.2 to reinforce the similarities and differences between the two models. The OY model assumes that the worker weighs the discounted utility value of immediate retirement at time $t$ against retirement at time $t+1$. The discounted utility value of immediate retirement at time $t$ is:

$$
V^{t}(t)=\sum_{s=t}^{\infty} \beta^{s-t}{ }_{s-t} \mathrm{p}_{x} U_{r}\left(\frac{C^{t}(s)}{Y(t)}\right)+\mathrm{L}
$$

and the discounted utility value at time $t$ by retiring at time $t+1$ is:

$$
V^{t+1}(t)=U_{w}\left(\frac{C(t)}{Y(t)}\right)+\sum_{s=t+1}^{\infty} \beta^{s-t}{ }_{s-t} \mathrm{p}_{x} U_{r}\left(\frac{C^{t+1}(s)}{Y(t)}\right)+\beta{ }_{1} \mathrm{p}_{x} \mathrm{~L},
$$

where:

$V^{t+1}(t)$ : discounted utility value function at time $t$ conditional on retirement at time $t+1$; 
$t$ : current time;

$\beta$ : personal discount factor (fixed parameter);

$C(s)$ : consumption at time $s$ while working $(=(1-\pi) Y(s)$, where $\pi$ represents the contribution rate);

$C^{t+1}(s)$ : pension consumption at time $s$ conditional on retirement at time $t+1\left(=P W(t+1) / \ddot{a}_{x+1}(t+\right.$ $1)$ );

$U_{w}(c)$ : utility function of working consumption; and

$U_{r}(c)$ : utility function of retirement consumption; and

$L$ : constant utility value gained from retirement leisure (fixed parameter, $0<\mathrm{L}<\infty$ ).

As with the option-value model, $C^{R}(s)$ and $C(s)$ are divided by current earnings, $Y(t)$, to avoid the corrosive effect of earnings inflation on the leisure utility $L$ and the disturbance terms. $Y(t)$ is an exogenous constraint in the maximization of utility.

We assume that the utility functions before and after retirement match those of the option-value model given in Eqs. (3) and (4), and therefore contain a leisure component of the multiplicative form $(k)$ after retirement. Other than its one-year framework, a second distinguishing feature in the OY model is that the individual also gains a constant and additive level of utility from leisure upon retirement (L). In addition to the multiplicative leisure $k$, we include the additive form for the realistic effect that it generates in the retirement decision (see Section 7). When discussing the tradeoffs between taking an additive versus multiplicative approach, Lachance (2008) explained "(t)here is no consensus in the literature as to how the utility of leisure should be incorporated in a life-cycle framework. Each approach has its advantages and disadvantages" (pg.161).

The discounted utility of one year's future working income net of pension contributions is the first term on the right-hand side of Eq. (11) and the sum of the second and third terms is the discounted utility of future pension benefits based on retirement thereafter.

Letting $E_{t}($.$) represent the individual's expectation about the future, based on information at$ time $t$, the retirement decision is made by comparing:

$$
E_{t}\left(V^{t}(t)\right)=\sum_{s=t}^{\infty} \beta^{s-t}{ }_{s-t} \mathrm{p}_{x}\left[\left(k \frac{C^{t}(s)}{Y(t)}\right)^{\gamma}+E_{t}(\xi(s))\right]+\mathrm{L},
$$

and

$$
\begin{aligned}
E_{t}\left(V^{t+1}(t)\right)= & \left(\frac{C(t)}{Y(t)}\right)^{\gamma}+\omega(t)+\sum_{s=t+1}^{\infty} \beta^{s-t}{ }_{s-t} \mathrm{p}_{x} \\
& \times E_{t}\left(\left(\frac{k C^{t+1}(s)}{Y(t)}\right)^{\gamma}+\xi(s)\right)+\beta_{1} \mathrm{p}_{x} \mathrm{~L} .
\end{aligned}
$$

The first formula, Eq. (12), is the expected discounted utility value of immediate retirement and the second, Eq. (13), is the expected discounted utility value of retiring in one year's time. At time $t$, $C^{t}(t)=P W(t) / \ddot{a}_{x}(t)$ and $C(t)=(1-\pi) Y(t)$ are known; consequently, $E_{t}($.$) in Eqs. (12) and (13) is$ 
dropped for $C^{t}(t)$ and $C(t)$. In Appendix B, we make a realistic modification by replacing the full expectation $\left(E_{t}().\right)$ with the individual's "best estimate".

Under the OY model, a worker chooses to retire if he/she does not expect to achieve a higher discounted utility value by delaying retirement another year; that is, similar to the option-value model, when :

$$
\begin{aligned}
E_{t}\left(V^{t+1}(t)\right)-E_{t}\left(V^{t}(t)\right)= & \left(\frac{C(t)}{Y(t)}\right)^{\gamma}+\sum_{s=t+1}^{\infty} \beta^{s-t}{ }_{s-t} \mathrm{p}_{x} E_{t}\left(\left(\frac{k C^{t+1}(s)}{Y(t)}\right)^{\gamma}\right)+ \\
& \beta_{1} \mathrm{p}_{x} \mathrm{~L}-\sum_{s=t}^{\infty} \beta^{s-t}{ }_{s-t} \mathrm{p}_{x}\left(k \frac{C^{t}(s)}{Y(t)}\right)^{\gamma}-\mathrm{L}+\mathrm{v}(t)
\end{aligned}
$$

is less than or equal to zero.

\subsection{Final Remarks on the Retirement Decision Models}

So far in this section, we have presented three hypothetical retirement decision models for a worker with a DC pension plan. The description of the OY and the option-value models in Sections 3.2 and 3.3 is, however, incomplete since the retirement decision formulas do not indicate how the workers form expectations of future circumstances $\left(E_{t}().\right)$. Appendix B provides this information. Further, the estimates for the retirement decision models' parameters are given in Table 1 and discussed in Appendix A.

\begin{tabular}{lcccccc}
\hline Option-Value Model Parameter & $\gamma$ & $k$ & $\beta$ & $\sigma_{v}$ & $\sigma_{\varepsilon}$ & \\
\hline Estimate & 0.769 & 1.9 & 0.786 & 0 & 0.015 & \\
\hline & & & & & & \\
\hline One-Year Model Parameter & $\gamma$ & $k$ & $L$ & $\beta$ & $\sigma_{v}$ & $\sigma_{\varepsilon}$ \\
\hline Estimates & 0.769 & 1.175 & 1.25 & 0.786 & 0 & 0.015 \\
\hline
\end{tabular}

Table 1: The selected parameter values for the option-value model and the OY model (see Appendix A for more details).

None of the three retirement decision models directly include factors that are common causes of involuntary retirement. In both the option-value and OY models, health and other individualspecific effects are considered to be indirectly captured by the random component. Survey evidence suggests that health is an important influence in the retirement decision. For instance, in the 2006 Statistics Canada report on "A Portrait of Seniors in Canada", 65\% of recent retirees indicated that they retired because it was financially possible (Turcotte, Liu, and Schellenberg, 2006). 27\% reported, however, that their reason for retirement was their health. In addition to health status, demographic characteristics such as gender, education, race, and marital status are not direct variables in any of the three models. Despite the Statistics Canada report, the role of health and other demographic characteristics in the retirement decision is unclear. For instance, Samwick (1998a) entered these explanatory variables in a probit model and found that they were insignificant determinants in the probability of retirement. Gustman and Steinmeir (2001) also found a lack of significance in several of these demographic variables in a similar study. In addition to demographic characteristics, it is possible that social norms and other behavioral biases are influential in the retirement decision, but they too are not directly included in the models examined in this study. 


\section{A Discussion of Retirement Decision Modeling}

In this section, we explore the validity of ascribing the full "forward-looking" feature of the optionvalue model to a DC participant. The option-value model arose at a time when DB plans dominated the pension world. Its motivation was the important influence of pension benefit incentives on the retirement decision (see Section 3.2). To explore its fit in a DC environment, therefore, this section compares and contrasts the distinct features and pension drivers within each of the two plan designs.

\subsection{The Uncertainty of DC Pension Income}

By definition, the benefit income under a DB pension is "defined". Given that the pension plan does not fold nor the plan rules change, the potential pension income at any future retirement age could be projected with relative ease with one, and sometimes two, pieces of information - years of service at retirement and, in some plans, earnings history (for instance, a final average plan would require the worker's earnings history ${ }^{8}$, while a specified dollar benefit plan would not). To make a projection, the earnings history of a retiree with an analogous career track could provide a reasonable benchmark.

A DC pension plan is simply a fund into which the employer and/or employee make contributions. The fund accumulates with contributions and investment returns until the employee leaves the plan, at which time he/she could have the choice to annuitize the funds, take the benefits as a lump sum or roll the funds over into another retirement account, subject to labour and tax laws. Workers covered under a DC scheme face tremendous uncertainty regarding the annual pension income that they will receive after retirement, as the unknown variables include future earnings, future investment performance, and future annuity prices if annuitization is desired. Unlike future earnings, however, there is no reliable benchmark for the future financial performance of a well diversified investment portfolio. For instance, based on a review of over 320 papers, Siegel (2005) concluded that historical equity risk premiums are not a good indicator for the future. Further, financial projections are outside the grasp of the ordinary person as research has shown that people generally (including those highly educated) exhibit a low level of financial literacy and are unable to make simple financial calculations (see Brown (2008) for a review of the literature supporting this assertion). Moreover, owing to the extreme uncertainty in future financial markets, even financial experts are unable to accurately predict the pension income under a DC pension plan design. For instance, Blake et al. (2001) carried out simulations under several asset models and showed that the replacement ratio under a DC plan is extremely risky relative to that under a DB plan - that is, the range of possible replacement ratios generated by a DC pension plan was very wide. This uncertainty increases as the projection is extended further and further into the future.

The complexity and inaccuracy of far-off DC benefit projections suggest that the retirement decision model for a DC participant should not assume that far-off projections are made by workers in every year that retirement is contemplated.

\footnotetext{
${ }^{8}$ If the plan indexes the worker's earnings by inflation in the benefit formula, then an inflation assumption is also necessary.
} 


\subsection{The Age-Neutral Incentives of DC Pension Plans}

In addition to having predictable benefits, the nature of the DB pension plan design typically includes strong economic incentives regarding the timing of retirement. It is, therefore, important and probable that DB plan workers take future pension opportunities into account when making retirement decisions. Generally, a DB plan can encourage an employee to delay retirement by:

- basing its retirement benefits on the worker's final wage earnings prior to retirement (this method is particularly effective if the worker's wage growth is high over his/her career), and/or

- reducing pension payments if the worker retires prior to becoming qualified for early retirement or the plan's normal retirement age.

A DB plan can promote early retirement by lowering their normal retirement age, providing generous early retirement benefits, offering retirement windows and/or limiting the permitted years of pension benefit accruals. In addition, a DB plan can be designed so that the pension benefits of employees who work beyond the normal retirement age are not actuarially adjusted, and consequently workers choosing to delay retirement would not be compensated for missed pension payments.

To illustrate the effect of the incentives historically provided by DB plans, Kotlikoff and Wise (1988) examined the average annual pension accrual as a proportion of earnings at each age for a number of DB pension plans in the US. The pension accrual between times $t$ and $t+1$ as a proportion of wage during that time $(\mathrm{Y}(\mathrm{t}+1))$ is:

$$
=[P W(t+1)-P W(t)(1+i)] / Y(t+1),
$$

where $i$ is the nominal interest rate and $P W(t)$ is the pension wealth associated with retirement at time $t$ (as defined in Section 3). The $P W(t)$ for a DB participant is generally equated to the expected discounted value of anticipated future retirement benefits (also known as the actuarial present value). The $P W(t)$ for a DC participant is simply the size of his/her pension fund at time $t$. Of the 1,183 DB plans examined by Kotlikoff and Wise, the average weighted accrual rate as a proportion of wage:

- jumped in the first year of vesting (pension wealth is zero before vesting),

- gradually grew until the early retirement age (age 55),

- leveled somewhat between ages 55 and 60 , and

- gradually declined until age 65 , after which the accruals became negative.

This pattern of pension accruals clearly encourages retirement between ages 55 and 60 , and certainly not past age 65 when there becomes a loss in pension wealth. Using 2,508 full-time employee data from Health and Retirement Study, Friedberg and Webb (2000) confirmed a similar pattern of age-related pension accruals for more contemporary US DB plans. They found that pension accruals rose and declined between ages 53 and 62, and became negative thereafter. The loss in pension wealth after the normal retirement age occurred because pension benefits were not actuarially adjusted - that is, "current benefits are foregone and future benefits are no longer raised" (ibid, pg. 5). These observed patterns were not as severe as they had once been, moreover, as the 
authors noted that 1986 US legislation mandated that workers continue to accrue credits beyond their normal retirement age and that the maximum allowable vesting period be reduced.

The strong influence of DB economic incentives on retirement behavior is not limited to the private sphere. In a comparison across 12 countries with very different social security programs, cultural histories and labour market institutions, Gruber and Wise (2004) uncovered the large effect of social security incentives on retirement decisions. Based on analyses from each country, they studied the relationship between social security provisions and labour force participation. They found that there was a similar and significant reaction among employees in all countries to social security retirement incentives and disincentives. For instance, in most of the countries studied, the social security benefits were not actuarially adjusted after the early retirement age. Consequently, pension accruals became significantly negative, and it is to this disincentive for continued work at older ages that the authors attributed the large decline in labour force participation of older persons.

Overall, DB pension plans are generally severely backloaded, having considerable accruals leading up to the age of early retirement and much lower, perhaps negative, accruals following the normal retirement age. On the other hand, in the absence of government added inducements, a DC plan does not provide any economic incentive to retire or not retire since the DC accruals are steady from one year to the next (Gustman and Steinmeier, 2001). We propose that a DC participant contemplating retirement would not find value in accounting for the accrual path of all future years since DC accruals are smooth - in essence, their lack of distinct incentive to retire at a particular future age removes the incentive to make the projection.

\subsection{The One-Year Retirement Decision Model}

The OY model assumes that workers consider only the potential benefit of delaying retirement by a single year when contemplating retirement rather than all future years as in the option-value model. In the OY model, the individual is not committing to retire in one year's time: he/she is simply using it as an informed point of comparison while considering retirement. The individual is aware that he/she can reevaluate his/her circumstances at any time if he/she decides to delay retirement. We chose a one-year scope because workers can generally have some certainty of retirement prospects one year in advance since many factors that affect the coming year's pension income, such as earnings, the risk-free rate of interest, and annuitization rates are known with some proximity at the beginning of the year (of course, any assurance is tainted by a risky investment strategy). Section 6 shows, moreover, that looking only one year ahead results in an optimal retirement decision owing to the age-neutral accruals of DC pension plans.

\section{Simulated Results of Retirement Decision Models}

This section presents the simulated retirement ages and replacement ratios that are generated under each retirement decision model. Figs. 1(a), (b) and (c) plot the mean retirement age of 3,500 simulated lifetimes against its standard deviation, for each of the 581 portfolios described in Section 2. Every simulation generates the retirement choice under a different evolution of economic variables and individual-specific random effects. The "X"s mark the efficient portfolios that lie on the efficient frontier - they are labeled T0 to T100, OY0 to OY100 and OV0 to OV100, and Table 2 gives 
their composition ${ }^{9}$. Fig. 1 can be better understood with the following remarks:

- From the perspective of a member, the indicators of success are young retirement ages with low volatility. Thus, the superior portfolios are those with points in the lower and leftward portion of the opportunity set.

- For each retirement decision model, there tends to be a cluster of dots for each level of equity exposure.

\begin{tabular}{lccccc}
\hline $\begin{array}{l}\text { Min Risk } \\
\text { Portfolio }\end{array}$ & $\begin{array}{c}\text { \% Index-linked } \\
\text { Cash }\end{array}$ & $\begin{array}{c}\text { \% Cash } \\
\text { \% Index-linked } \\
\text { Bond }\end{array}$ & $\begin{array}{c}\text { \% Bond } \\
\text { \% Equity }\end{array}$ \\
\hline T0 & 0 & 0 & 70 & 30 & 0 \\
T10 & 0 & 0 & 60 & 30 & 10 \\
T20 & 0 & 0 & 50 & 30 & 20 \\
T30 & 0 & 0 & 40 & 30 & 30 \\
T40 & 0 & 0 & 30 & 30 & 40 \\
T70 & 0 & 0 & 0 & 30 & 70 \\
T80 & 0 & 0 & 0 & 20 & 80 \\
T90 & 0 & 0 & 0 & 10 & 90 \\
T100 & 0 & 0 & 0 & 0 & 100 \\
OY0 & 0 & 0 & 90 & 10 & 0 \\
OY10 & 0 & 0 & 90 & 0 & 10 \\
OY20 & 0 & 0 & 70 & 10 & 20 \\
OY30 & 0 & 0 & 50 & 20 & 30 \\
OY40 & 0 & 0 & 40 & 20 & 40 \\
OY50 & 0 & 0 & 30 & 20 & 50 \\
OY60 & 0 & 0 & 20 & 20 & 60 \\
OY70 & 0 & 0 & 0 & 30 & 70 \\
OY90 & 0 & 0 & 0 & 10 & 90 \\
OY100 & 0 & 0 & 0 & 0 & 100 \\
OV0 & 0 & 0 & 100 & 0 & 0 \\
OV10 & 0 & 0 & 90 & 0 & 10 \\
OV20 & 0 & 0 & 70 & 10 & 20 \\
OV30 & 0 & 0 & 60 & 10 & 30 \\
OV40 & 0 & 0 & 50 & 10 & 40 \\
OV50 & 0 & 0 & 40 & 10 & 50 \\
OV60 & 0 & 0 & 10 & 30 & 60 \\
OV80 & 0 & 0 & 0 & 20 & 80 \\
OV100 & 0 & 0 & 0 & 0 & 100 \\
\hline
\end{tabular}

Table 2: Moving from the top of the efficient frontiers to the bottom, this table lists the portfolio mix for T0 to T100, OY0 to OY100 and OV0 to OV100 in Fig. 1.

\footnotetext{
${ }^{9}$ Efficient portfolios are the portfolios that carry the lowest risk for each given age of retirement. T50, T60, OY80 and OV90 are not listed since they do not lie on the efficient frontier.
} 
(a)

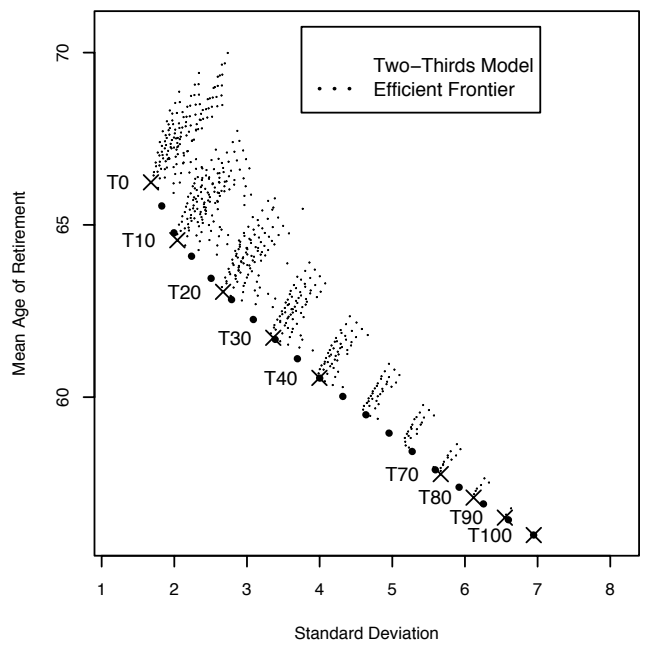

(c)

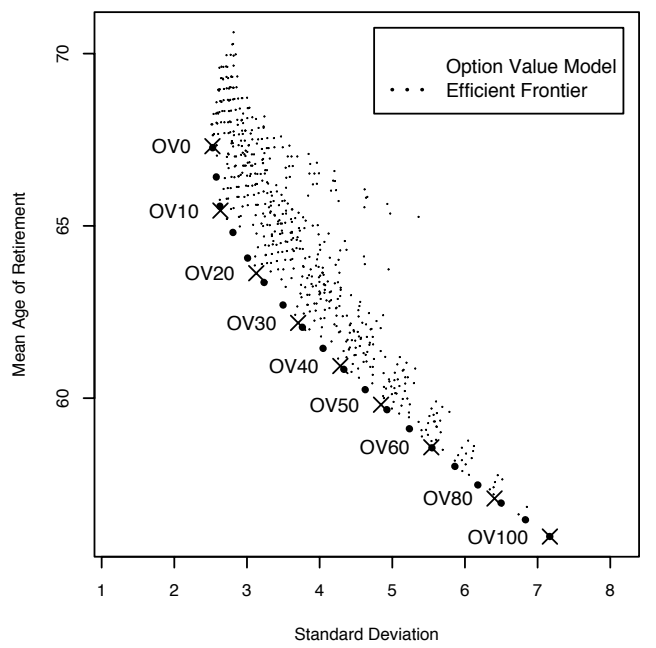

(b)

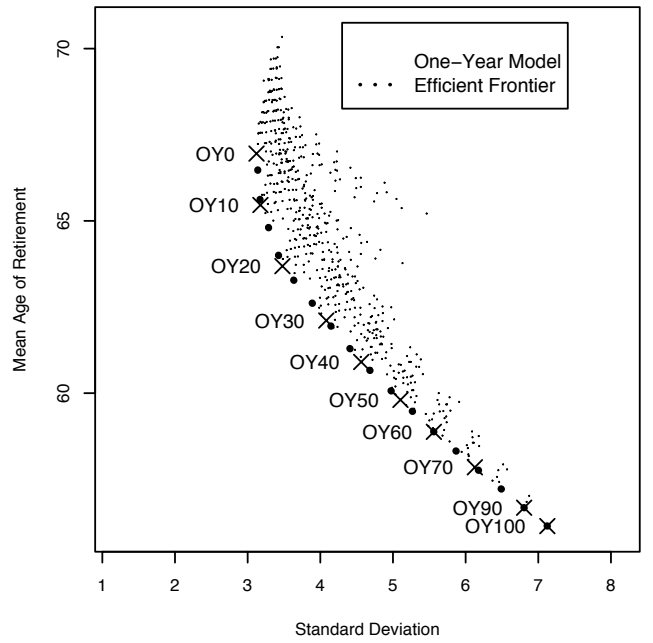

Figure 1: Simulated opportunity sets generated by 581 different asset allocation strategies (small dots) under each retirement decision model: (a) two-thirds, (b) OY and (c) option-value. The efficient frontier is marked in each plot by a large dotted line. Table 2 lists the composition of the efficient portfolios T0 to T100, M0 to M100 and OV0 to OV100 (marked by "X"s on the efficient frontiers). 
Fig. 2 graphs the empirical cumulative distribution function (CDF) of the retirement age and of the replacement ratio for a pure equity and a pure index-linked bond investment strategy:

Plot (a): Retirement age CDF for a 100\% index-linked bond investment strategy;

Plot (b): Retirement age CDF for a 100\% equity investment strategy;

Plot (c): Replacement ratio CDF for a 100\% index-linked bond investment strategy;

Plot (d): Replacement ratio CDF for a 100\% equity investment strategy;

Each point on the CDF curve shows the probability that the retirement age/replacement ratio falls below a particular level. We generate the CDF for an equity portfolio and an index-linked bond portfolio because they are both efficient assets under all the retirement decision models (that is, they are included in the efficient portfolios).

For all three retirement decision models, a greater weighting in index-linked bonds is the most efficient investment decision when equities are avoided. In Fig. 1, the lowest risk efficient portfolio under both the option-value model and the OY model is 100\% index-linked bonds. For the twothirds model, the lowest risk portfolio is $70 \%$ index-linked bonds and $30 \%$ bonds. None of the efficient portfolios include cash and index-linked cash. As was observed in MacDonald and Cairns (2007), allocating funds into equities hugely reduces the average retirement age - in fact, moving from no equities to a $100 \%$ equity portfolio reduces the average retirement age by over 10 years under each retirement decision model. The retirement age uncertainty also increases with the level of equity exposure; comparing the CDFs in Figs. 2(a) and (b), nevertheless, a member is much more likely to have an opportunity to retire earlier if they hold a pure equity portfolio than a pure index-linked bond strategy, or any other combination of assets (that is, the majority of the CDF in plot (b) lies to the left of the corresponding CDF in plot (a)). As was found in Lachance (2003) and MacDonald and Cairns (2007), having a flexible rather than fixed retirement age allows the worker to take on more investment risk, and benefit from the generally higher returns.

The four distributions delivered by the OY model in Figs. 2(a), (b), (c), and (d) are similar to the option-value model. The replacement ratio CDFs in plots (c) and (d) are unsurprisingly nearly vertical under the two-thirds model, with a small arch on top to capture the individuals whose replacement ratio surpasses the two-thirds mark in a one-year period. The CDFs of the optionvalue and OY models rise less steeply from 0 to 1 relative to the two-thirds model, indicating a wider distribution of replacement ratios and retirement ages.

An important finding of this section is that all three retirement decision models suggest that DC pension plan designs create a smooth, and potentially wide, distribution of retirement ages. This stands in sharp contrast to DB plan designs where workers are given sharp economic incentives to retire at particular ages owing to the non-linearity of the pension accruals (see Section 4). Since each retirement decision model assumes that financial wealth affects the retirement decision, bull markets produce earlier retirement ages while bear markets produce delayed retirement ages. The precise range of the retirement age distribution is driven by the portfolio's exposure to equities. For instance, in Figs. 2(a) and (b), the reduced volatility of index-linked bond returns generates a narrower range of retirement ages than equities. 
(a)

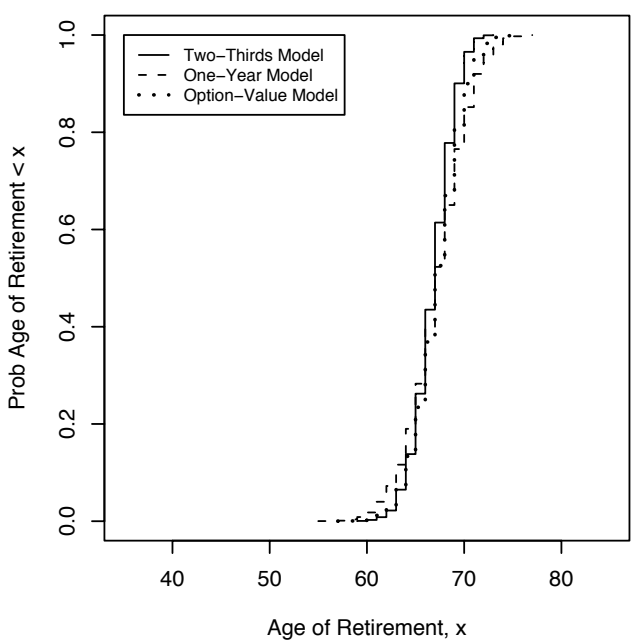

(c)

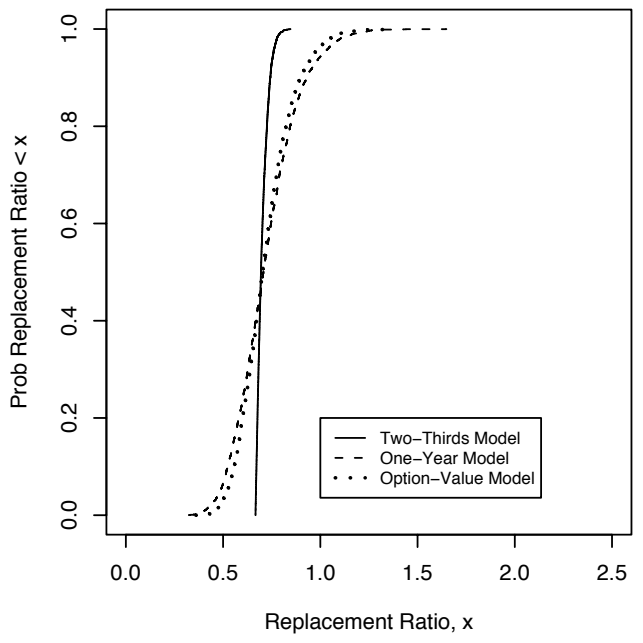

(b)

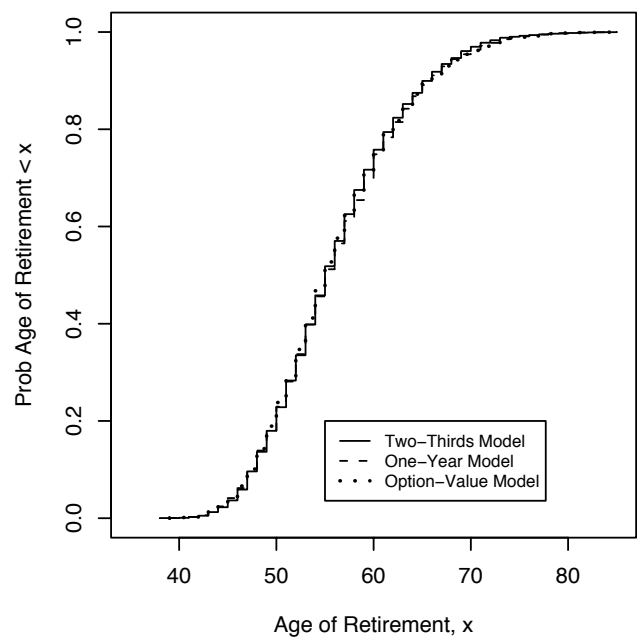

(d)

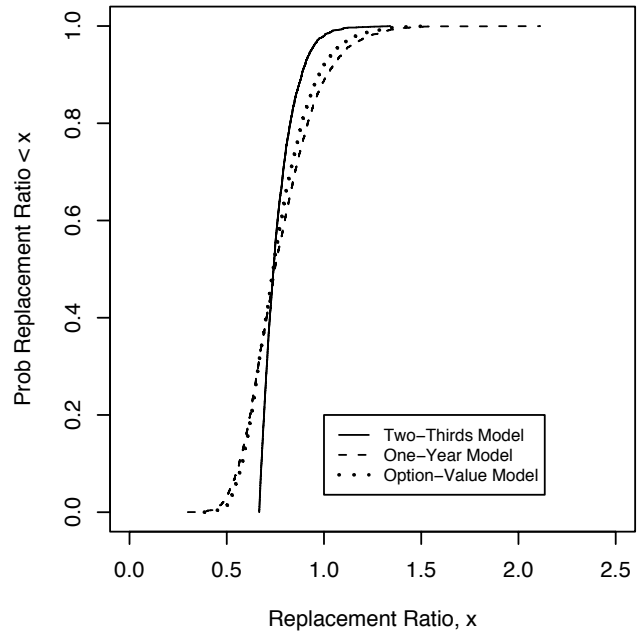

Figure 2: Simulated empirical cumulative distribution functions of the age of retirement (plots (a) and (b)) and the replacement ratio (plots (c) and (d)) from a 100\% index-linked bond (plots (a) and (c)) and a $100 \%$ equity (plots (b) and (d)) investment strategy. 


\section{Optimal and less complex}

We next ask how the results of the OY model are affected if, like in the option-value model, the DC participant considers all future years in his/her retirement decision rather than only the coming year. This section finds that the retirement choice would remain the same under reasonable economic conditions, thus placing the OY model among the structural models of retirement timing, such as the original option-value model, which optimize over the entire projected lifetime consumption of the worker.

We begin in Fig. 3 by showing that the retirement choice generated by the OY model is always optimal over the projected future lifetime of the worker if he/she projects future economic variables using their long-term means and no individual-specific random effect ${ }^{10}$. The y-axis of Fig. 3 is the discounted utility value that a 65 year-old worker anticipates to derive from retirement at each future age - that is, $E_{t}\left(V^{R}(t)\right)^{11}$, where (using the same notation as in Section 2):

$$
V^{R}(t)=\sum_{s=t}^{R-1} \beta^{s-t}{ }_{s-t} \mathrm{p}_{x} U_{w}\left(\frac{C(s)}{Y(t)}\right)+\sum_{s=R}^{\infty} \beta^{s-t}{ }_{s-t} \mathrm{p}_{x} U_{r}\left(\frac{C^{R}(s)}{Y(t)}\right)+\beta^{R-t}{ }_{R-t} \mathrm{p}_{x} \mathrm{~L} .
$$

The $\mathrm{x}$-axis is the possible future retirement ages, $x+R-t$. Fig. 3 presents the results for three levels of accumulated DC wealth. In the first scenario, the worker's accumulated funds can purchase an immediate annuity that replaces $47 \%$ of his/her current earnings (solid line), the second scenario shows a $67 \%$ replacement (dashed line), and the third scenario shows a $87 \%$ replacement (dotted line). We choose $67 \%$ as the central value as it is the replacement ratio that would trigger retirement at age 65 based on our assumptions, and we also test a 20\% change in both directions. The three curves are unimodal, indicating that the one-year rule is optimal. If the anticipated discounted utility associated with retirement at age 65 is higher than that associated with retirement at age 66, then unimodality implies that there cannot be a maximum at any later age, and therefore to retire immediately at age 65 is optimal. Alternatively, if the anticipated discounted utility associated with retirement at age 66 is higher than that arising from immediate retirement, then it is optimal to defer retirement (i.e. the maximum is later). Either way, determining the discounted utility values for ages 65 and 66 is sufficient for the plan member to make an optimal decision.

We next simulated the retirement decision using the same 3,500 lifetime economic and personal scenarios for the 581 different portfolios examined in Fig. 1. We found that the OY model nearly always generated the same retirement decisions regardless of whether the worker considers all future retirement opportunities (the modified OY model ${ }^{12}$ ) or solely that in the coming year (the original OY model). Fig. 4 graphs the efficient frontier for both models. Although not perceptible, the efficient frontier of the modified OY (dashed line) is very slightly higher than the original efficient frontier (solid line). This occurred because the modified OY generated a later retirement age, resulting in a slight average increase of 0.001 year across the tested portfolios. For instance, of the 581 portfolios examined, the pure equity portfolio produced the highest number of mismatched retirement ages and this amounted to approximately only a quarter of a percent of the simulations

\footnotetext{
${ }^{10}$ This scenario is for illustration purposes and we later relax these assumptions.

${ }^{11}$ Note that we replace the full expectation with the "anticipated value" (see Appendix B).

${ }^{12}$ In particular, for the modified OY model, Eq. (11) from Section 3.3 is replaced by Eq. (16) and retirement occurs if $E_{t}\left(V^{t}(t)\right) \geq E_{t}\left(V^{R}(t)\right)$ for all $R>t$. This is the equivalent to the option-value model, except with a fixed leisure additive component.
} 


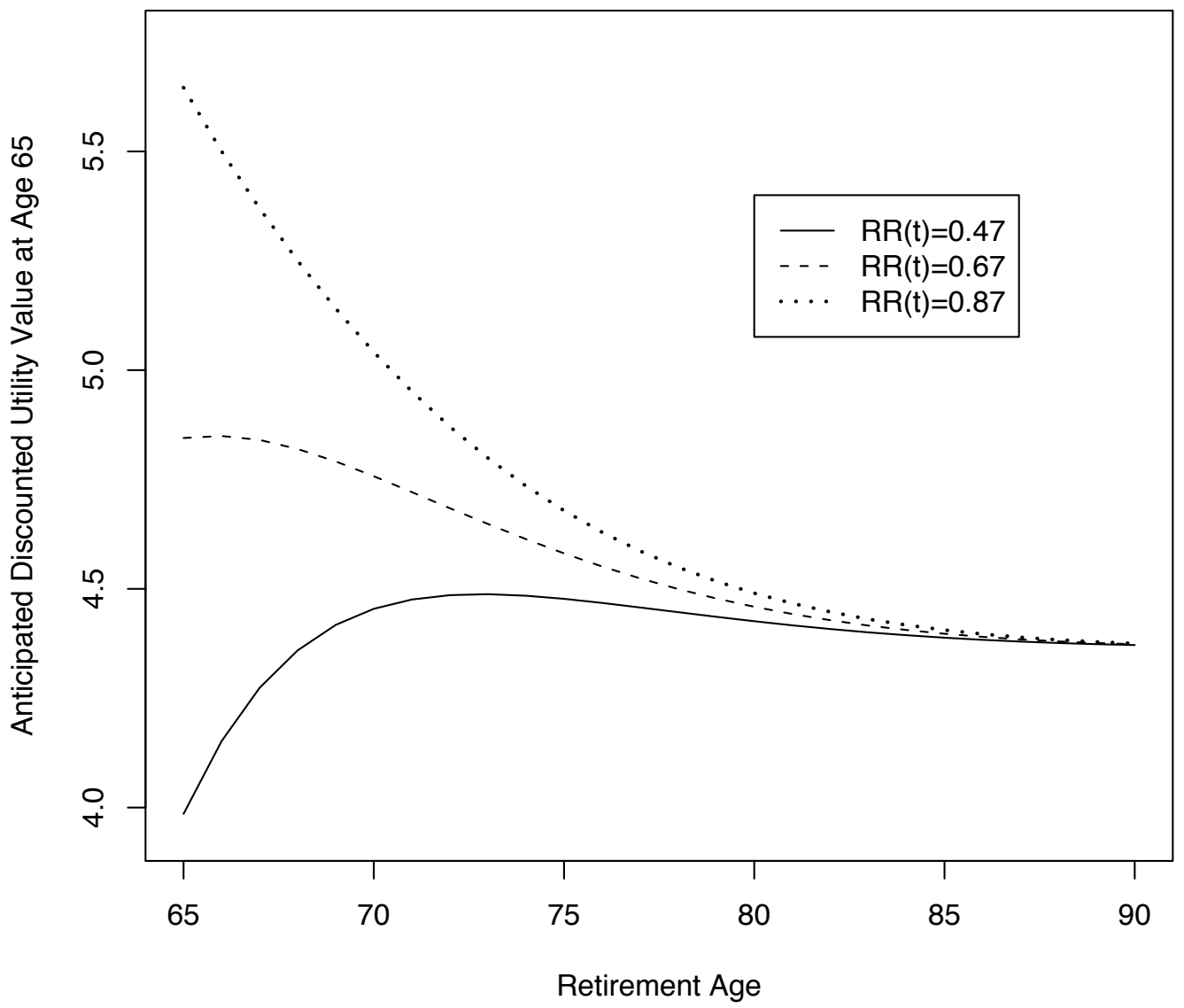

Figure 3: The anticipated discounted utility value of retiring at each future year for a 65 year-old, based on three current levels of replacement ratio: 47\% (solid line), 67\% (dashed line) and 87\% (dotted line) 
and the overall effect was a change of only 0.01 year in the average simulated retirement agd ${ }^{3}$. The few exceptions occurred in scenarios where the interest rates were irregular (the vast majority of the simulations with irregular interest rates did produce, however, the same retirement age). For example, if the risk-free real rate of interest plunges, then the model would ascribe abnormally large increases to future income and pension benefits beyond the coming year owing to the implied high inflation, thus possibly generating a later retirement age in the modified OY model than the original OY model.

We also did the same test for the option-value model - that is, we investigated the effect on the retirement decision if the worker weighed the anticipated discounted utility value of retirement in only the subsequent year as opposed to all future years. We similarly found that the retirement decision was nearly always the same. This suggests that it is the age-neutral retirement incentives of a DC plan design, more than the formula specifications particular to the OY model, that removes the benefit of projecting beyond one year when determining the value of delaying retirement. An implication of this finding is that, if a worker was inclined to make far-off financial forecasts beyond one year, the age-neutral accruals of the DC plan would render the additional effort of no effect on the retirement decision.

\section{Replacement ratio behavior under each decision model}

The strict two-thirds target ignores the possibility that participants could have different income replacement thresholds depending on their changing circumstances. Although individuals expect a higher replacement ratio if they work and save longer, we believe that the minimum replacement ratio for retirement should decline with age for seniors, which we define as a person age 65 and older (see Turcotte, Liu, and Schellenberg (2006) for a discussion on the definition of "senior"). The following four arguments explain our rationale.

1. As time wears on and the constraints of aging begin to set in, such as declining health, an elderly individual could settle for a lower replacement ratio as he/she increasingly finds continuing to work more difficult. This argument is validated by the realistic existence of agerelated limitations on employment and their influence on the retirement decision (see Section 3.4 ).

2. Aging individuals could increasingly build-up their personal savings to compensate for any shortfall in their DC pension (that is, save more towards retirement than $\pi Y(t)$ ), particularly if their investments have witnessed bad market performance ${ }^{14}$. The notion that people compensate for their deficient pension with personal savings was shown in an OECD study that assessed adequacy of retirement provision across nine OECD countries (Disney, d'Ercole and Scherer, 1998). Taking into account all sources of retirement income, they found a surprising level of uniformity between the levels of replacement ratios across the countries, despite the large differences in the composition of the retirement income packages. They suggested that individuals target a desired replacement ratio by adjusting to institutional and market constraints through such means as individual savings. There is also the possibility that, as people

\footnotetext{
${ }^{13}$ If interest rates became negative in any simulation, we assumed that workers use $0 \%$ for projection purposes. Assuming negative interest rates when making projections would have produced some further simulated differences between the models.

${ }^{14}$ Although this is a possibility, we did not include this potential behavior in our model.
} 


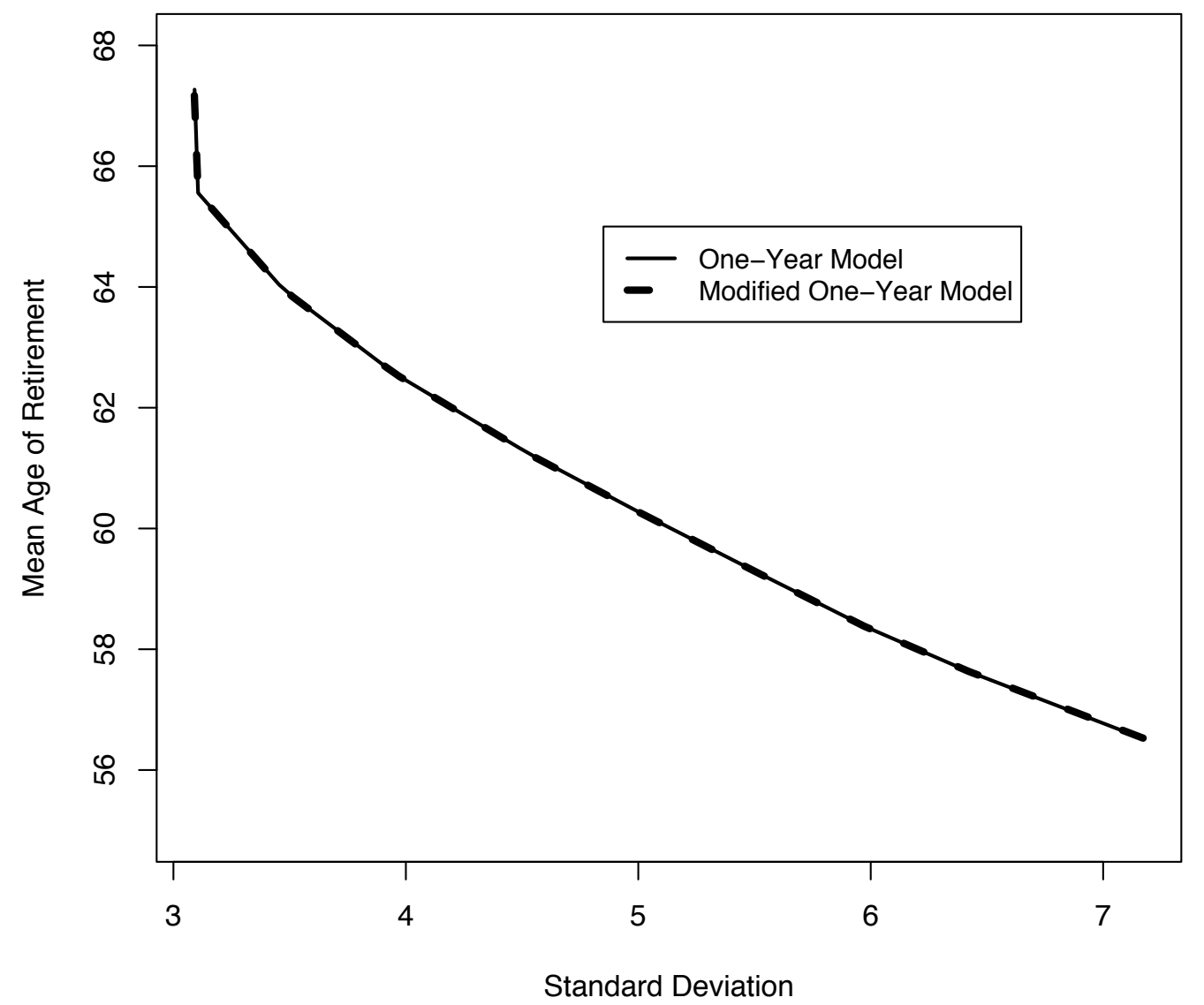

Figure 4: The graph displays the efficient frontiers of the original OY model as well as a modified version of the OY model that considers all future pension opportunities. 
grow older and their children become independent, they are willing to sell their house and downsize their shelter as a means to make-up a replacement ratio deficit.

3. As the inclination to retire becomes stronger with age, seniors could be willing to reduce their spending so as to exit the workforce. In a recent focus group study of retirees, nearly all felt "sure they can reduce their spending if their financial situations change" (Greenwald, Bryck, and Sondergeld, 2006). Brzozowski and Lu (2006) found that retirees have a greater ability to reduce spending than workers owing to the increased time that can be allocated to home-production and efficient shopping.

4. Finally, as seniors grow older, their expenses could also decrease since children move from home, the mortgage becomes paid-off, senior discounts exist on some goods and services, and traveling as well as other high cost leisure activities could become less feasible owing to the frailty that accompanies old age. Then again, medical expenses that are not covered by the state or private insurance could rise with the deterioration of health, suggesting the opposite effect. MacDonald et al. (2010a) ascertained that the necessary costs of living could potentially decrease with age if good health is maintained since the personal circumstances of the elderly are generally more affordable, for reasons listed above. The paper emphasized, however, that it is a senior's personal circumstances and not their age that are the primary influences on the necessary cost of living. If age-related expenses do progressively alleviate the pressure of a high income replacement, this would allow older individuals to accept lower replacement ratios to maintain their standard of living.

For advanced ages under the OY model, we find that there is an inverse relationship between an individual's minimum replacement ratio and age. Fig. 5 graphs the replacement ratio necessary to induce retirement at each age under each retirement decision model. As with the rest of this study, we use the "best estimate" projections described in Appendix B. For fund projection purposes and calculating the fair annuity value, we assume that the current rates are at their long-term means and we remove the discounted utilities' disturbance terms by letting $\xi(t)=\omega(t)=0^{15}$. For the twothirds model, the necessary replacement ratio is simply two-thirds. Under the other two models, it is the replacement ratio threshold that satisfies Eq. (7) $=0$ (option-value model) or Eq. (14) $=0$ (OY model). Under the OY model, the replacement ratio threshold increases moderately until the socially normative retirement ages begin at age $55^{16}$ when the ratio levels somewhat for 15 years. After age 70, the required threshold begins to drop rapidly. Specifically, the pension income needed to lure a 55 to 70 year-old employee into retirement is approximately two-thirds of his/her current earnings. By age 75 , a worker is satisfied with a $65.3 \%$ wage replacement in exchange for retirement (marked by an ' $X$ ' in Fig. 5), 56.2\% by 85 and $48.4 \%$ suffices once he/she reaches age 90. On the contrary, the option-value model produces replacement ratios that rise with age over the range 33 to 78 , and only falling thereafter ${ }^{17}$.

The fixed additive leisure component in the OY model is responsible for the inverse relationship between a senior's age and his/her minimum replacement ratio. As the expected number of future

\footnotetext{
${ }^{15}$ We relax this assumption and test non-zero values at the end of this section.

${ }^{16}$ For instance, in the US, nearly $90 \%$ of respondents from the Health and Retirement Study retired after age 54 (Gustman and Steinmeier, 2005). Please note that this information was given in a graph in an earlier version of the paper (dated 2002), but was removed in the actual 2005 publication.

${ }^{17}$ The mortality rates plateau slightly at age 83 , causing a slight jump in the replacement ratios for both the option-value and the OY models (see Section 2 for mortality table used in study).
} 


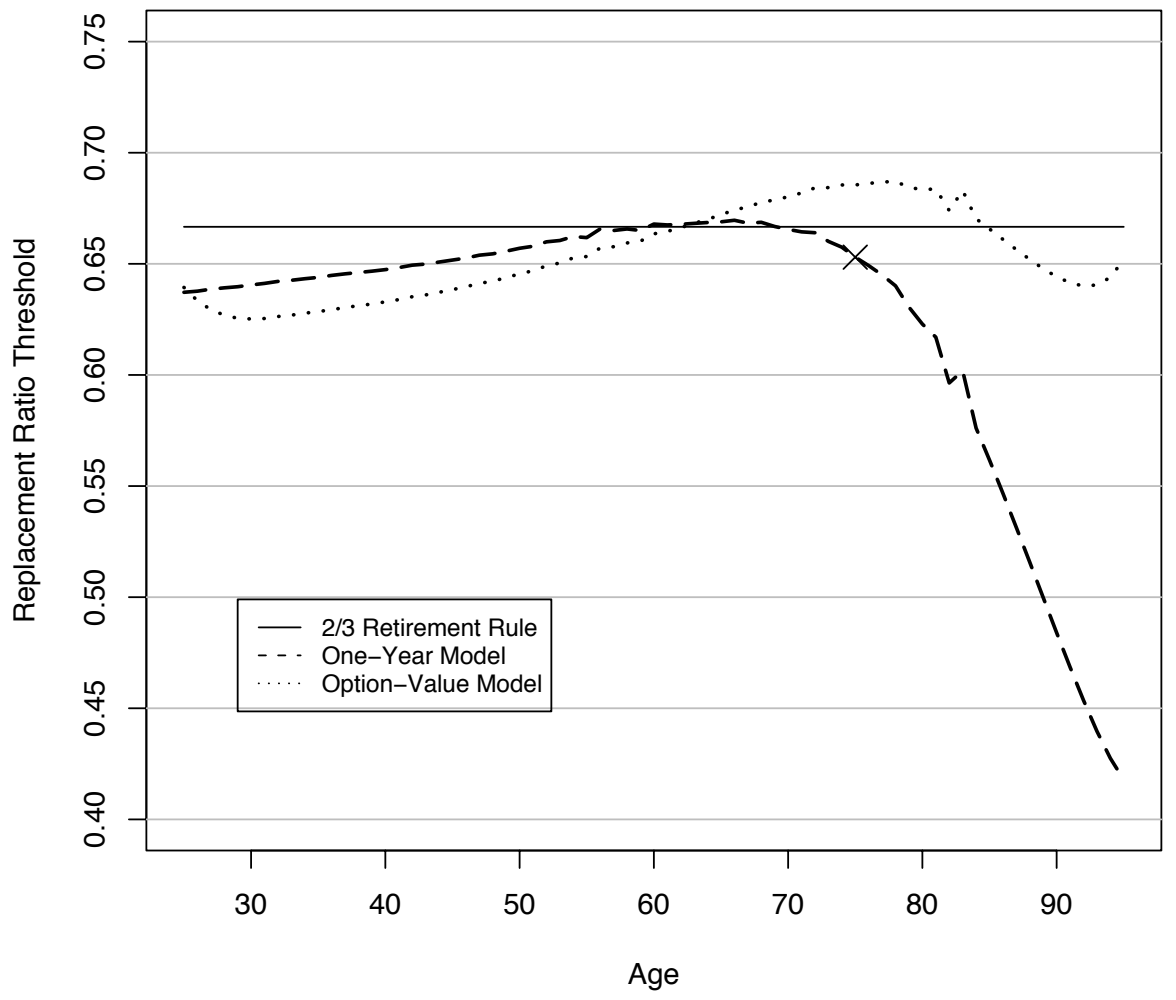

Figure 5: The replacement ratio required to induce retirement at each age according to the twothirds model (solid line), the OY retirement decision model (dashed line), and the option-value model (dotted line). The "X" marks the replacement ratio for age 75 in the OY model. 
consumption years declines, less years contribute to the summation in Eqs. (10) and (11). Consequently, an aging individual progressively gives more weight to the value of leisure by reducing the importance they place on future income. The fixed additive leisure component, therefore, explains the decline in the threshold.

An alternative means to express the growing importance of leisure is to vary $L$ with age, using either a multiplicative approach or an additive approach. For simplicity in calibrating the model to empirical data, many studies choose a fixed leisure parameter (such as the previously published studies that used the option-value model, as well as Lachance (2008)). The benefit of the OY model is that the researcher can continue to make this simplifying assumption while still capturing the theory that seniors would increasingly place more emphasis on leisure and less on the potentially greater income that could be gained by delaying retirement.

We explore the parameter values' influence on the relationship between the replacement ratio and age in Figs. 6 (OY model) and 7 (option-value model). All of the plots are on the same scale. Increasing the leisure parameter estimates for both retirement decision models has the unsurprising effect of accelerating an individual's retirement age by lowering the required replacement ratio, and vice versa, as shown in Figs. 6(a) and (b) for the OY model and Fig. 7 (a) for the option-value model. In Figs. 6(c) and 7(b), reducing $\beta$ diminishes the importance of future income on the retirement decision, affecting the retirement pattern by pushing down the required replacement ratio. Increasing $\beta$ produces the opposite effect. As for the risk parameter, $\gamma$, we explain in Appendix B that $\gamma$ 's role in the retirement decision is unclear since workers project future pension benefits and working income streams deterministically and without any future risk. In Figs. 6(d) and 7(c), we find that workers bearing a lower $\gamma$ than the original will drop their desired replacement ratio and consequently retire earlier. For workers with a relatively higher $\gamma$, the reverse occurs. Finally, we also examine the disturbance terms' influence by testing the impact of a shift of one standard deviation in each year (positive and negative):

$$
\begin{aligned}
v(t) & =(-1,0,1) \times \sqrt{\operatorname{Var}(v(t))} \\
& =(-1,0,1) \times \sqrt{\sigma_{v}^{2}+s \sigma_{\varepsilon}^{2}}
\end{aligned}
$$

where $s$ is the time since entry into the pension plan ( $s=0$ at age 25). In Figs. 6(e) and 7(d), the effect of including the disturbance term evenly tilts the curve up or down but does not greatly affect the shape. Taken as a whole, it appears that the retirement decision model itself is the primary dictator of the shape of the relationship between age and replacement ratio while the parameter values, within reason, bear little consequence to this relationship.

\section{Future Work}

The next step in this study would be to test the three models against empirical data, at which point the labour laws and tax and transfer systems of the country from where the data originates would need to be incorporated. For instance, the consumption stream should be calculated on an after-tax basis. Further, depending on the particulars, the OY model may need to be adapted to account for any public policy incentives to retire at particular ages (such as penalties on withdrawals of DC accounts prior to a particular age). We suggest that the analyst adjusts the model to also include in the 
(a)

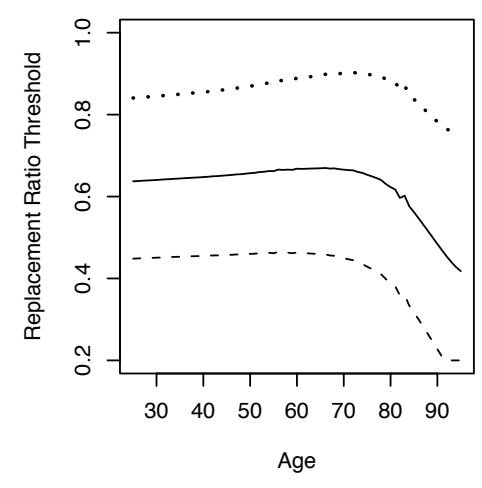

(c)

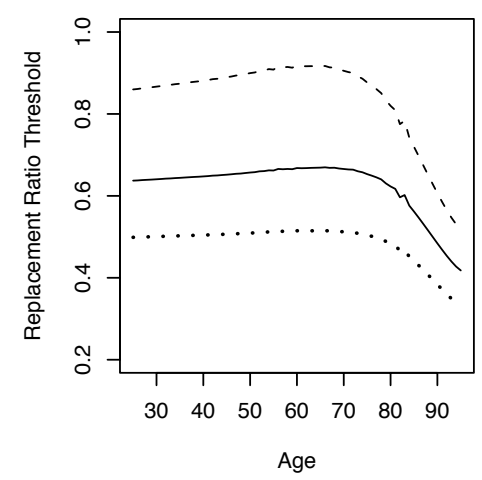

(e)

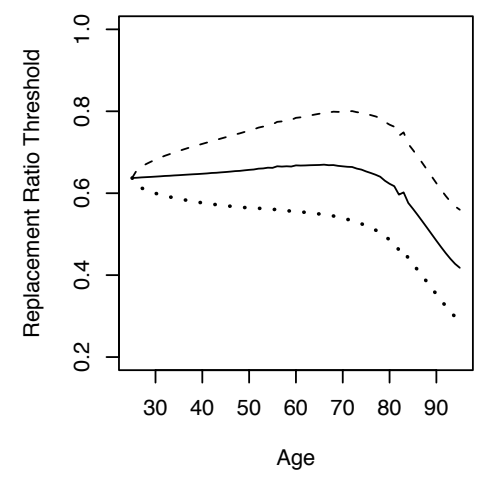

(b)

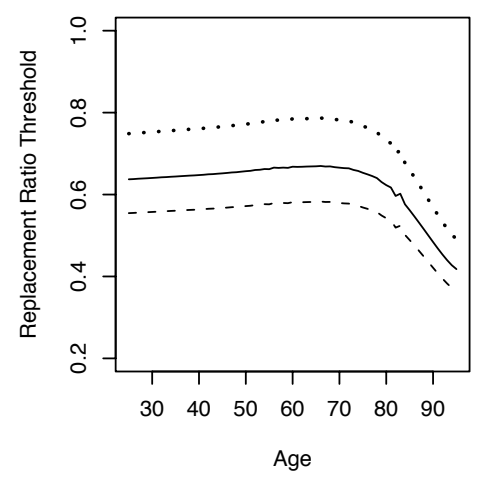

(d)

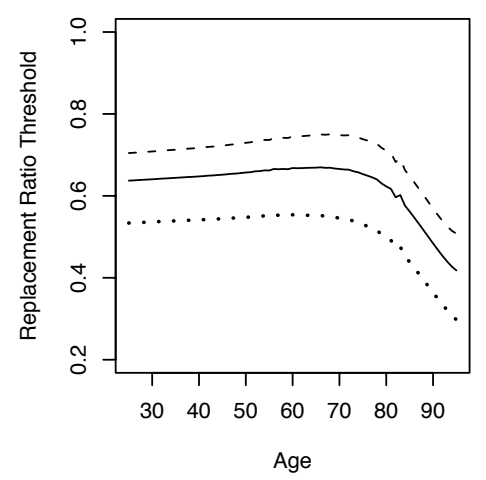

Figure 6: The replacement ratio threshold at each age under the OY retirement decision model, letting (a) $L=0.5$ (dotted), 1.25 (solid) and 2 (dashed), (b) $k=1$ (dotted), 1.175 (solid) and 1.35 (dashed), (c) $\beta=0.722$ (dotted), 0.786 (solid) and 0.85 (dashed), (d) $\gamma=0.538$ (dotted), 0.769 (solid) and 1 (dashed), and (e) $v(t)=-0.216$ (dotted), 0 (solid) and 0.216 (dashed). 
(a)

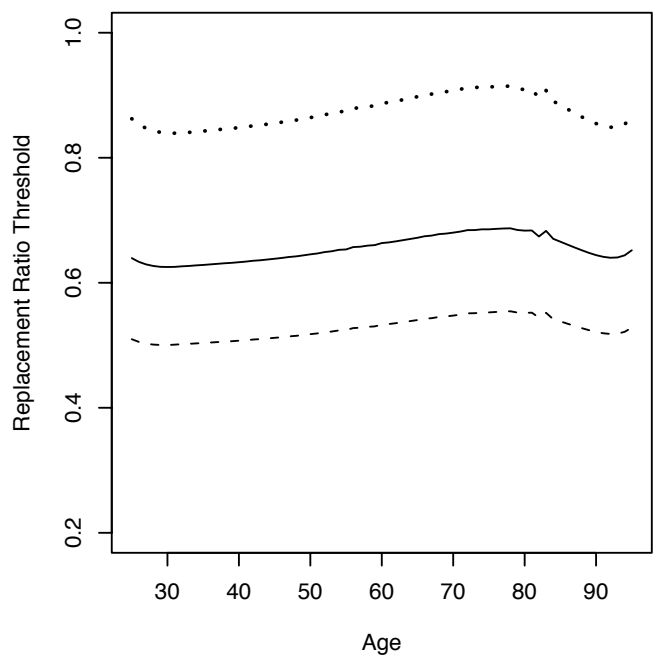

(c)

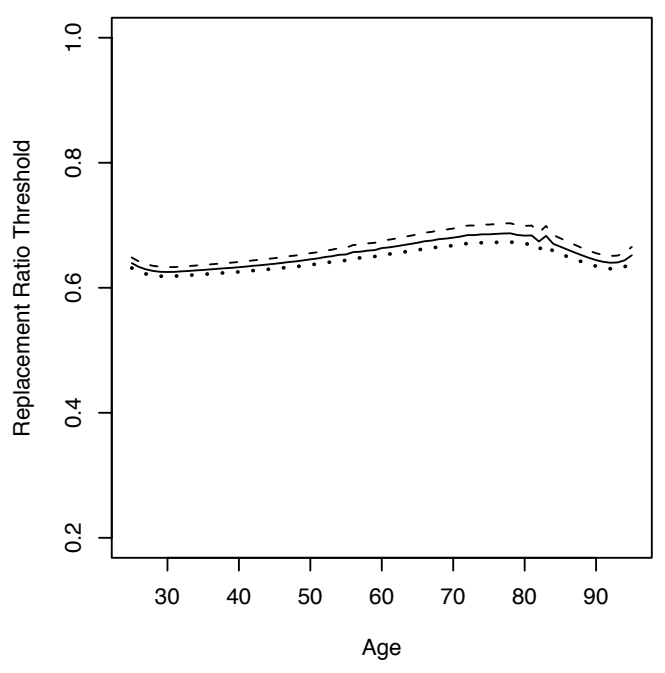

(b)

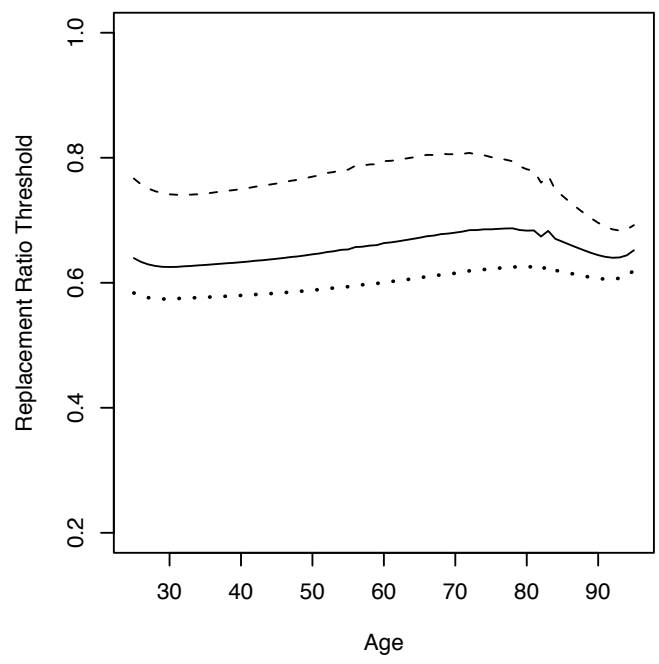

(d)

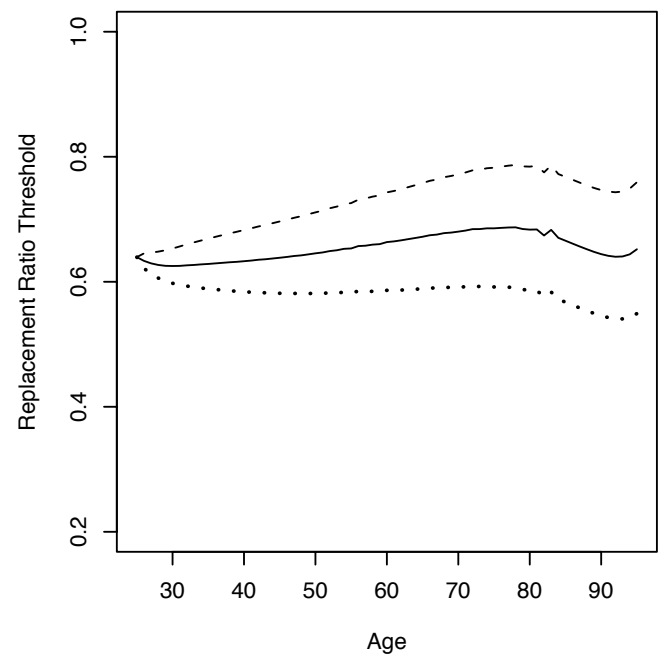

Figure 7: The replacement ratio threshold at each age under the option-value retirement decision model, letting (a) $k=1.4$ (dotted), 1.9 (solid) and 2.4 (dashed), (b) $\beta=0.722$ (dotted), 0.786 (solid) and 0.85 (dashed), (c) $\gamma=0.538$ (dotted), 0.769 (solid) and 1 (dashed), and (d) $v(t)=$ -0.216 (dotted), 0 (solid) and 0.216 (dashed). 
decision the potential value of retiring in the first year that the incentive takes effect. Alternatively, if the incentives are sufficiently great that retirement prior a particular age is generally suboptimal, the analyst could assume that retirement is not contemplated until after this age, and only thereafter apply the OY model. Another relevant addition would be to include the cost of expenses and profits in the management of the DC plan, the pricing of financial assets and the purchase price of annuities. In a large scale, this could be accomplished by adjusting the financial rates of return. Lastly, when adapting the model to a particular country's population, the heterogeneity among individuals should be modeled, such as within the parameter estimates for the utility functions (the rate of time preference and the value that retiring workers place on leisure) and the retirement savings characteristics (the investment strategy, career path, contribution rate, etc.).

\section{Conclusion}

In this paper, we examine the implied underlying behavior of a DC participant who makes his/her retirement decision according to one of three retirement decision models. We first consider the two-thirds model, which assumes that a DC participant sets a two-thirds replacement ratio target and exits the workforce once that target is achieved. We next look at the popular option-value model that optimizes the decision over all projected future retirement opportunities. Finally, we develop the one-year (OY) model. This model, although similar in its use of utility functions to the option-value model, postulates that the DC participant's ability and desire to gauge future retirement opportunities is limited to the coming year.

By stochastically simulating the economic variables - inflation, financial market returns and annuitization rates - we found that across all three retirement decision models the index-linked bond was the best performing asset for low-risk portfolios in terms of offering the youngest retirement age with the least amount of risk. If the member can tolerate some risk, it is in his/her best interest to invest the majority of his/her funds in equities owing to the much lower average retirement age that results from an equity portfolio. We caution, however, that our model is estimated from historical data, and the high equity premiums could potentially not continue in the future (Siegel, 2005).

In a study that tested wealth shocks on retirement timing, Sevak (2002) wrote "Unlike DB pensions, DC pensions do not provide workers with sharp incentives to retire at particular ages. Whereas DB pensions have non-linear accrual rates, DC accrual should be relatively smooth. Thus, the growth of DC pension plans could account for the 'flattening out' of male retirement ages... While the rules of the pension plan may not suggest spikes in retirement at particular ages, variation in the value of accounts due to market performance may cause fluctuation in retirement timing due to wealth effects. This has not yet been examined in the literature" (pg. 2). The findings of our study support these assertions - that is, owing to the age-neutral pension accruals of DC plans and the implied influence of wealth on a DC participant's choice to retire within all three models, retirement is smoothly distributed over a substantial range of ages, and the magnitude of the range is a direct result of the uncertainty in the financial market (more risky investment strategies generate larger ranges).

As Lumsdaine et al. (1990) explained, empirical analysis reveals the superior model as being that which better approximates the variables that govern actual retirement behavior. In other words, the better it mimics actual retirement decisions, the better the model. Our paper is not intended to prove that the OY model is the closest approximation to actual DC retirement behavior. We 
would require data and a statistical analysis to make such a claim. Rather, it is to explore the implied underlying retirement behavior of each model in a DC environment. From a theoretical perspective, we found three advantages of the OY model over the option-value model:

- Its underlying theory for retirement decision-making is more feasible given the distinct features and pension drivers of a DC pension plan, where:

- Far-off financial forecasting is not worthwhile since:

* future DC pension income is extremely unpredictable and

* there are no age-related incentives in the pension accruals.

- Retirement prospects can generally be known with some certainty one year in advance (although a risky investment strategy could still result in a sudden and unexpected change in wealth).

- In addition to being computationally less burdensome, the OY model's retirement decisions are optimal over the worker's projected lifetime under the vast majority of scenarios (the very few exceptions being unusual financial market projections). In other words, the OY model produces the same retirement decision regardless of whether the value of immediate retirement is weighed against all future years or simply the subsequent year. The underlying reason is that DC pension plans lack financial incentives to retire or not retire at particular ages; consequently, the age-neutral pension accruals enable the worker to make an optimal decision by looking only one year ahead.

- Finally, there is a more logical relationship between the worker's decision to retire and his/her current retirement savings and age. Unlike the option-value model, the minimum replacement ratio that triggers retirement under the OY model declines with age once a worker is in their mid-sixties and begins a steep descent after age 70. We believe that this is likely the general behavior of older individuals, who would tolerate a lower replacement ratio with each passing year since:

- continuing to work could be less viable or welcomed;

- they could compensate for a deficient replacement ratio through additional personal savings or by tapping into other financial resources (such as housing equity);

- they could be more apt to reduce spending so that retirement becomes financially viable; and/or

- their financial needs could decrease with age.

We also prefer the OY model to the two-thirds model because:

- The OY model assumes a realistic variety of replacement ratios at retirement.

- The OY model is forward-looking, but limits itself to the relatively certain immediate future.

As DC pension plans continue to spread and empirical data emerges, we expect future work investigating DC retirement behavior to grow. A useful area for future work would be to test the retirement decision models against empirical data. 


\section{References}

Arias, E., 2004. United States life tables 2002. National Vital Statistics Reports 53(6), 1-39.

Asch, B., Haider, S. J., Zissimopoulos, J., 2005. Financial incentives and retirement: evidence from federal civil service workers. Journal of Public Economics 89, 427-440.

Belloni, M., 2008. The option value model in the retirement literature: the trade-off between computational complexity and predictive validity. European Network of Economic Policy Research Institutes Research Reports 50.

Blake, D., Cairns, A. J. G., Dowd, K., 2001. Pensionmetrics: stochastic pension plan design and value-at-risk during the accumulation phase. Insurance: Mathematics and Economics 29(2), 187215.

Blake, D., Cairns, A. J. G., Dowd, K., 2003. Pensionmetrics 2: stochastic pension design during the distribution phase. Insurance Mathematics and Economics 33 (1), 29-47.

Broadbent, J., Palumbo, M., Woodman, E., 2006. The shift from defined benefit to defined contribution pension plans - implications for asset allocation and risk management. Prepared for a working group on institutional investors. Global Savings and Asset Allocation established by the Committee on the Global Financial System. 1-59.

Brown, J. R., 2008. Financial education and annuities. OECD Journal:General Papers 3.

Burkhauser, R.V., Butler, J.S., Gumus, G., 2003. Option value and dynamic programming model estimates of social security disability insurance application timing. IZA Discussion Paper 941, Bonn, Germany.

Brzozowski , M., Lu, Y., 2006. Home cooking, food consumption and food production among the unemployed and retired households .Social and Economic Dimensions of an Aging Population Working Paper 151. Hamilton, Ontario, Canada : McMaster University.

Cairns, A.J.G. 2004. nterest Rate Models. Princeton University Press, New Jersey.

Canadian Institute of Actuaries. 1996. Meeting the retirement income needs of coming generations. Report of the Task Force on Pension Plan Coverage, Ottawa.

Coile, C., Gruber, J., 2000. Social Security and retirement. National Bureau of Economic Research Working Paper 7830, Cambridge, MA.

Coronado, J.L., Perozek, M.G., 2001. Wealth effects and the consumption of leisure: retirement decisions during the stock market boom of the 1990s. Working Paper, Federal Reserve Board, Washington, DC.

Disney, R., d'Ercole, M.M., Scherer, P., 1998. Resources during retirement. In Maintaining Prosperity In An Ageing Society: the OECD Study on the Policy Implications of Ageing. Organisation for Economic Co-operative and Development Ageing Working Paper AWP 4.3., Paris.

Dus, I., Maurer, R., Mitchell, O. S., 2004. Betting on death and capital markets in retirement: a shortfall risk analysis of life annuities versus phased withdrawal plans. Pension Research Council Working Paper, The Wharton School, University of Pennsylvania, Philadelphia. 
Euwals, R., van Vuuren, D.J., Wolthoff, R.P., 2006. Early retirement behavior in the Netherlands: evidence from a policy reform, IZA Discussion Paper 1992. IZA Discussion Paper 1992, Bonn, Germany.

Friedberg, L., Webb, A., 2000. The impact of 401(k) plans on retirement. Economics Working Paper Series 2000-30, Department of Economics, University of California at San Diego, UC San Diego.

Greenwald, M., Bryck, S.A., Sondergeld, E.T., 2006. Spending and Investing in Retirement: Is There a Strategy? Society of Actuaries and LIMRA International, Inc.

Gruber, J., Wise, D.A. (Eds.). 2004. Social Security and Retirement Around the World: MicroEstimation, Chicago: University of Chicago Press.

Gustman, A.L., Steinmeier, T.L., 2001. Retirement and wealth. National Bureau of Economic Research Working Paper 8229, Cambridge, MA.

Gustman, A.L., Steinmeier, T.L., 2005. The Social Security early entitlement age in a structural model of retirement and wealth. Journal of Public Economics 89, 441-463.

Hakola, T.,1999. Race for retirement, VATT-Research Reports 60, Helsinki, Finland.

Harris, A.R., 2001. Modeling retirement behavior: a test of the option value model using the health and retirement study. Working Paper.

Horneff, W. J., Maurer, R. H., Mitchell, O. S., Stamos, M. Z., 2007. Money in motion: dynamic portfolio choice in retirement. Pension Research Council Working Paper, The Wharton School, University of Pennsylvania, Philadelphia.

Hurd, M.D., Loughran, D.S., Panis, C.W.A., 2003. Effects of raising the social security retirement ages on retirement and disability. RAND Manuscript.

Kotlikoff, L., Wise, D., 1988. In: Summers, L. (Ed.), Pension Backloading, Wage Taxes, and Work Disincentives. In: Tax Policy and the Economy, vol. 2. MIT Press.

Lachance, M-E., 2003. Optimal investment behavior as retirement looms. Working Paper, Wharton School, University of Pennsylvania, Philadelphia.

Lachance, M-E. 2008. Pension reductions: can welfare be preserved by delaying retirement? Journal of Pension Economics and Finance 7, 157177.

Lumsdaine, R.L., Stock, J.H., Wise, D.A., 1990. Three models of retirement: computational complexity versus predictive validity. National Bureau of Economic Research Working Paper 3558, Cambridge, MA.

Lumsdaine, R.L., Stock, J.H., Wise, D.A.,. 1992. Pension plan provisions and retirement: men and women, medicare, and models. National Bureau of Economic Research Working Paper 4201, Cambridge, MA.

Lumsdaine, R.L., Stock, J.H., Wise, D.A., 1994. Retirement incentives: the interaction between employer-provided pensions, social security, and retiree health benefits. National Bureau of Economic Research Working Paper 4613, Cambridge, MA.

MacDonald, B-J., Cairns, A.J.G., 2007. The impact of de pension systems on population dynamics. North American Actuarial Journal 11 (1), 1748. 
MacDonald, B-J., Cairns, A.J.G., 2009. Getting feedback on defined contribution pension plans. Journal of Risk and Insurance 76 (2), 385417.

MacDonald, B-J., Andrews, D., and Brown, R., 2010. The Canadian elder standard-pricing the cost of basic needs for the canadian elderly. Canadian Journal on Aging 29 (1), 3956.

Merton, R., 1969. Lifetime portfolio selection under uncertainty: the continuous time case. Review of Economics and Statistics 51, 247257.

Milevsky, M.A., Young, V.R., 2007. Annuitization and asset allocation. Journal of Economic Dynamics and Control 31 (9), 313877.

Mitchell, O.S, Moore J.F., 1998. Retirement wealth accumulation and decumulation: new developments and outstanding opportunities. Journal of Risk and Insurance 65 (3), 371400.

Piekkola, H., Deschryvere, M., 2004. Retirement decisions and option values: their application regarding finland, belgium and germany. The Research Institute of the Finnish Economy Discussion Paper 951, Helsinki, Finland.

Samwick, A.A., Wise, D.A., 2001. Option value estimation with HRS data. Conference Volume Draft.

Samwick, A.A., 1998a. New evidence on pensions, social security, and the timing of retirement. National Bureau of Economic Research Working Paper 6534, Cambridge, MA.

Samwick, A.A., 1998b. Discount rate heterogeneity and social security reform. Journal of Development Economics 57, 117146.

Sevak, P., 2002. Wealth shocks and retirement timing: evidence from the nineties. Working Paper 2002-027, Michigan Retirement Research Center.

Siegel, J.J., 2005. Perspectives on the equity premium. Financial Analysts Journal 61 (6), 6173.

Stock, J.H. Wise, D.A., 1990a. Pensions, the option value of work, and retirement. Econometrica $58(5), 11511180$.

Stock, J.H. Wise, D.A., 1990b. The pension inducement to retire: an option value analysis. National Bureau of Economic Research Working Paper 2660, Cambridge, MA.

Turcotte , M., Liu , J., Schellenberg, G., 2006. A portrait of seniors in Canada. Statistics Canada, Ottawa, Ontario, Canada.

Vasicek, O.E., 1977. An equilibrium characterisation of the term structure. Journal of Financial Economics 5 (2), 177188.

\section{Appendix}

\section{A The Function and Estimate of Each Parameter}

This appendix explains the parameter estimates for both the OY and option-value models. We begin by explaining the theoretical function of the models' parameters and then proceed by discussing our choice for their estimates. 
The parameter $\beta$ measures an individual's rate of time preference specific to the retirement decision. If $\beta=1$, then future income is given the same weight as current income. Relative to current payments, future payments are increasingly given less weight in the retirement decision as $\beta$ falls below 1 .

The relative risk aversion, $1-\gamma$, describes the worker's sensitivity to fluctuations in the flow of his/her future income stream (Mitchell and Moore, 1998). A value of 1 for $\gamma$ implies a risk-neutral preference with respect to income. In other words, utility is a linear function of income. A value less than 1 represents a risk averse individual who desires a stable stream of wage and pension income over his/her entire future. For example: if there is a $50 \%$ probability of receiving a payment of $\$ 5,000$ and an equal probability of receiving $\$ 10,000$, then the certainty equivalent for a risk averse individual with $\gamma=.5$ is only $\$ 7,285$, which is below the expected value of $\$ 7,500^{8}$.

If a dollar of retirement benefit income is given the same value as a dollar of working income, then $k=1$. A value greater than one indicates that the utility associated with income while enjoying leisure in retirement is greater than during employment. Similarly, the gain from leisure, $L$, represents the additional utility value placed on retirement; the higher the estimate, the sooner a worker retires.

The parameter estimates in the existing option-value model literature have numerous drawbacks. Stock and Wise in their 1990a paper, as well as in subsequent work that utilized the optionvalue model such as Stock and Wise (1990b) and Lumsdaine et al. (1990), estimated the parameters of the model with a single large firm's data rather than population-level data. Samwick (1998a) expressed his reservations in large firm records as a source of retirement data since personal records do not include details such as whether the worker's termination was on account of retirement or simply changing employers. Samwick did not, however, estimate the parameters from data, but set $\gamma=0.75, k=1.5$ and $\beta=0.97$, explaining that $\beta$ and $k$ "could not be simultaneously identified with any precision" from the population-level data (pg.18). Samwick (1998a) is one author among many summarized in Euwals et al. (2006) who calculated the option-value $\left(E_{t}\left(V^{R}(t)\right)-E_{t}\left(V^{t}(t)\right)\right)$ as a variable in a reduced-form retirement decision model and who did not personally estimate the parameters from data but fixed them at particular values (between $0.75-1.00$ for $\gamma, 1.5-3.1$ for $k$ and $0.03-0.05$ for the discount rate, $1 / \beta-1$ ).

Studies that attempted to estimate the option-value model from general population data included Harris (2001) and Hurd et al. (2003), both of whom employed the Health and Retirement Study data. Both studies ran into difficulties during the parameter estimation process. Hurd et al. attempted to stabilize the results by re-parameterizing the original utility function developed in Stock and Wise (1990a). Their estimates remained, however, exceptionally different from all previous studies, such as $k=146$ for women. Harris (2001) also had trouble estimating parameters from the Health and Retirement Study data, finding that the values were inconsistent with their theoretical functions and the estimates from previous studies that were based on firm-level data.

Another limitation in the previously published option-value model literature is the omission of the auto-correlation in the disturbance term modeling (see Eqs. (5) and (6) for this component of the model). Stock and Wise (1990a) found much similarity in the results of a three year model with auto-correlated $v(s)$ and a single-year model with no auto-correlation of the $v(s)$ to the previous year. Thereafter, numerous authors assumed independent disturbance terms between years. Included among them were Hurd et al. (2003) who, when faced with 16,844 person-years observa-

\footnotetext{
${ }^{18}$ This example is similar to that presented in Stock and Wise (1990a).
} 
tions of Health and Retirement Study data on men aged 55 to 70, realized it would be troublesome to incorporate the auto-correlation of the $v(s)$ 's from one year to the next. Similarly, Burkhauser et al. (2003) assumed that the disturbance terms were independent over people and time. Many authors, such as Stock and Wise (1990b), estimated the option-value model with a single year's data and considered only the retirement probability in a single year, effectively removing the possibility of correlating the disturbance terms between years.

In the absence of population-level parameter estimates, we use the original firm-level estimates given in Stock and Wise (1990a), with some exceptions as outlined below. We do some sensitivity analysis in Section 7 where we show that the results in that section are unaffected by the exact parameter estimates for $\gamma, k$ and $\beta$ given that their values lie within the tested ranges.

The individual disturbance term plays an important role if made to follow a random walk in accordance with the original option-value model as described in Stock and Wise (1990a). Setting $\rho=1$, Stock and Wise (1990a) estimated $\gamma, k, \beta, \sigma_{v}$ and $\sigma_{\varepsilon}$ to equal $0.769,1.665,0.786,10,800$ and 8,100 , respectively. When the model is applied in a DC environment with this set of parameter values and our economic assumptions, the simulated pattern of retirement is unreasonable. The workers are generally simulated to retire before age 30 or never at all. Owing to the auto-correlation feature, the disturbance term tends to become largely negative or positive over the career of the participant, causing it to swamp the other deciding factors in Eq. (7). High positive values for $v(t)$ generate older retirement ages with more lucrative replacement ratios. Very negative values have the opposite effect.

The source of the strange retirement behavior is the size of the original disturbance term parameters, $\sigma_{v}=10,800$ and $\sigma_{\varepsilon}=8,100$. There are three explanations behind the large estimates. First, Stock and Wise (1990a) assumed only members above age 50 contemplate retirement. Second, although Stock and Wise (1990a) used data containing individual retirement decisions for three consecutive years, they made the simplifying assumption that the members consider retirement for the first time at the beginning of those three years. Consequently, the $\sigma_{i}$ and $\sigma_{\varepsilon}$ estimates incorporate the build-up of auto-correlation from all years earlier than age 50, and possible older, which could grow large in absolute terms. Finally, Stock and Wise (1990a) based their estimates of $q$ and $\sigma_{\varepsilon}$ on actual consumption levels. In our model, the consumption levels are divided by current earnings; accordingly, $\sigma_{v}$ and $\sigma_{\varepsilon}$ should be divided by the average earnings to the power of $\gamma$.

The first exception in following Stock and Wise (1990a)'s choice of parameter estimates is that we let $\sigma_{v}=0$ and $\sigma_{\varepsilon}=0.015$. The implication is that everyone at age 25 has the same circumstances with regard to retirement and that the individual random effects become more important for individuals with each passing year. In Figs. 6(e) and 7(d) at the end of Section 7, we show that the $\sigma_{v}$ and $\sigma_{\varepsilon}$ estimates generate a reasonable distribution of replacement ratio thresholds at each working age (that is, the lowest replacement ratio needed to satisfy $E_{f}\left(V^{t}(t)\right) \geq E_{t}\left(V^{R^{*}}(t)\right)$ ). Within one standard deviation, the disturbance terms alone add to the OY model's replacement ratio threshold an additional $11 \%$ in both directions at age 60 , and $14 \%$ at age 80 . In the case of the option-value model, it adds $8 \%$ and $10 \%$. Had we increased the $\sigma_{\varepsilon}$ estimate from 0.015 to 0.05 , the range would increase to $38 \%$ in both directions at age 60 and $46 \%$ at age 80 for the OY model, and $26 \%$ and $33 \%$ for the option-value model.

We find that the net effect of the parameter combination $\gamma=0.769, k=1.665, \beta=0.786, \alpha=0$ and $\sigma_{\varepsilon}=0.015$ simulates average ages of retirement that are slightly older than the two-thirds model for each investment strategy. To make the results more comparable across the retirement decision models, while not changing our general conclusions, we increase the estimate for $k$ to 1.9. The point 
of leveling the results is for fairer comparison. Our aim is to match the average retirement age and replacement ratio for a member with a $60 \%$ equity portfolio across all three models - letting $k=1.9$ satisfies this condition. This is the same criteria that we apply in setting the OY model parameters. Letting $L=1.25$ and $k=1.175$ brings the OY model results in line with the other two models.

Setting $\beta$ equal to 0.786, as was estimated by Stock and Wise (1990a), could appear unusually low since it implies a high discount factor. Empirical evidence presented in both Samwick (1998b) and Gustman and Steinmeier (2005) showed, however, that the majority of individuals have a time preference rate above the long-term nominal risk-free rate in our model (see MacDonald and Cairns (2007)). In fact, $33 \%$ of individuals have a time preference rate of over $15 \%$ (that is, $\beta<0.87$ ), suggesting an "essentially an earn-it-and-spend-it mentality" (Gustman and Steineier, 2005, pg.451). Second, as we note above, Section 7 tests this estimate, along with the others, and we observe that our general conclusions in that section are unchanged by a somewhat higher or lower value.

\section{B Future Projection Assumptions for the Option-Value and One-Year Models}

This appendix explains how workers form expectations of future working income and retirement benefits in our study.

People in general are not financially literate (Brown, 2008). Except for the extremely financially competent savers, calculating the full expectation of future income $\left(E_{t}(.) \mathrm{s}\right.$ in Eqs. (7) and (13)) is an unrealistic behavior since the individual would need to account for future risk and determine the distribution of future pension wealth, earnings and annuitization rates that could emerge from the current state of the economy and his/her circumstances. The capabilities of the average worker would suggest a less sophisticated approach and we make a realistic modification to the full expectation $E_{t}($.$) . While deciding to retire, we assume that individuals deterministically project a single$ stream of future cashflows. We let $\varepsilon_{t}($.$) represent an individual's single "best estimate" or "antic-$ ipated value" of the future based on information at time $t$. Sections B.1 and B.2 incorporates the "best estimate" assumption into the relevant formulas.

Further, we assume that the worker projects inflation, investment returns and the cost to annuitize using the prevailing financial market risk-free bond prices. For instance, the return that a worker would expect to receive on invested funds equals the return on a currently priced risk-free zero-coupon bond with a corresponding maturity date. The pricing of bonds in the Vasicek model incorporates both the risk-free rate's long-term mean as well as its current value (see the appendix in MacDonald and Cairns (2007) for the precise formulas, the parameter estimates, the sources of data and more details of this study's stochastic asset-return and earnings model $)^{9}$.

Annuities are priced using the following formula:

$$
\ddot{a}_{x}(t)=\sum_{s=t}^{\infty} P_{1}\left(x_{1}(t), t, s\right)_{s-t} \mathrm{p}_{x}
$$

where ${ }_{s-t} \mathrm{p}_{x}$ is the probability of survival in the next $s-t$ years for someone aged $x . P_{1}\left(x_{1}(t), t, s\right)$ is the price at time $t$ of a risk-free zero-coupon bond that matures at time $s$ and the stochastic state variable, $x_{1}(t)$, is the instantaneous risk-free rate of interest at time $t . P_{3}\left(x_{3}(t), t, s\right)$ is similarly used

\footnotetext{
${ }^{19}$ For an introduction to the Vasicek and other interest rate models, see Cairns (2004).
} 
in the upcoming equations and it is the price at time $t$ of a zero-coupon index-linked bond that matures with $C P I(s) / C P I(t)$ at time $s$, where $\mathrm{CPI}(\mathrm{t})$ is the consumer price index at time $t$ and $x_{3}(t)$ is the instantaneous real risk-free rate of interest at time $t$. The nominal and real risk-free rates of interest, $x_{1}(t)$ and $x_{3}(t)$, follow the one factor model proposed by Vasicek (1977), as do the pricing formulas for $P_{1}\left(x_{1}(t), t, s\right)$ and $P_{3}\left(x_{3}(t), t, s\right)$ (see MacDonald and Cairns (2007)).

\section{B.1 Option-value Model}

We fist rewrite Eq. (7) to include the "best estimate" assumption:

$$
\begin{aligned}
& E_{t}\left(V^{R}(t)\right)-E_{t}\left(V^{t}(t)\right) \\
\approx & \sum_{s=t}^{R-1}\left(\frac{\beta^{s-t}{ }_{s-t} \mathrm{p}_{x}}{Y(t)^{\gamma}}\right) \varepsilon_{t}\left(C(s)^{\gamma}\right)+\sum_{s=R}^{\infty} \beta^{s-t}{ }_{s-t} \mathrm{p}_{x}\left(\frac{k}{Y(t)}\right)^{\gamma} \varepsilon_{t}\left(C^{R}(R)^{\gamma}\right) \\
& -\sum_{s=t}^{\infty} \beta^{s-t}{ }_{s-t} \mathrm{p}_{x}\left(\frac{k \times C^{t}(t)}{Y(t)}\right)^{\gamma}+\sum_{s=t}^{R-1} \beta^{s-t}{ }_{s-t} \mathrm{p}_{x} v(t) .
\end{aligned}
$$

In Eq. (18), the $\varepsilon_{t}($.$) notation should be interpreted as "best estimate of" or "anticipated value of".$ We write the $\approx$ symbol in any formula where $\varepsilon_{t}($.$) is substituted for E($.$) . Plan members project$ each of the key elements deterministically and $\varepsilon_{t}($.$) is evaluated part by part:$

$$
\varepsilon_{t}\left(C(s)^{\gamma}\right)=\left(\varepsilon_{t}(C(s))\right)^{\gamma}
$$

and

$$
\varepsilon_{t}\left(k^{\gamma} \times C^{R}(R)^{\gamma}\right)=k^{\gamma}\left(\varepsilon_{t}\left(C^{R}(R)\right)\right)^{\gamma} .
$$

The "best estimate" approach is reduced to determining future earnings and pension benefits: $\varepsilon_{t}(C(s))$ and $\varepsilon_{t}\left(C^{R}(R)\right)$ for $R>t$ at time $t$ (note that $C^{R}(s)$ and $C(s)$ are known at time $s=t$ ).

Stock and Wise (1990a) took the same approach when setting

$$
E_{t}\left(K B_{s}(r)\right)^{\gamma}=\left(K \hat{B}_{s}(r)\right)^{\gamma},
$$

where $B_{s}(r)$ was their notation for $C^{R}(s)$ and $\hat{B}_{s}(r)$ represented the projected pension benefit that was calculated from the observed past and current earnings (see footnote on pg.1164 in that paper).

Digressing for a moment, it is interesting that having removed any element of future risk by adopting a "best estimate" deterministic approach, the meaning behind the risk aversion parameter, $\gamma$, is less clear. The "best estimate" model treats future cashflows as though they are known in advance by the workers with absolute certainty, thereby blurring the function of the risk parameter to diminish the appeal of a risky future for a risk averse individual. Regardless of the worker's level of risk aversion, his/her decision to retire is unaffected by the wide range of possible future outcomes generated by a risky investment strategy. Rather than weighing the risk attached to future cashflows, the model employs the utility functions as a means to decide between a range of deterministic streams of cashflows: one stream for each future retirement date $(R \geq t)$. In Section 7, we find that a slightly increased $\gamma$ creates later retirement ages by raising the member's minimum replacement ratio for retirement. Likewise, lowering $\gamma$ decreases the minimum replacement ratio, thus creating earlier retirement ages. 
The "best estimate" consumption during each year of additional employment, $\varepsilon_{t}(C(s))$, is the anticipated earnings less the $\pi$ pension contribution $\left(=\varepsilon_{t}((1-\pi) Y(s))\right)$. The earnings model outlined in MacDonald and Cairns (2007) comprises of price inflation, real wage growth and merit increases. The anticipated inflation equals the implied excess return of a zero-coupon bond yielding the current nominal risk-free rate of interest $\left(=1 / P_{1}\left(x_{1}(t), t, s\right)\right)$ over a zero-coupon bond yielding the current real risk-free rate of interest $\left(=1 / P_{3}\left(x_{3}(t), t, s\right)\right)$. Using the long-term real wage growth, $\mu_{5}$, as the anticipated real wage growth, the "best estimate" earnings at time $s$ is:

$$
\varepsilon_{t}(Y(s))=Y(t) \frac{P_{3}\left(x_{3}(t), t, s\right)}{P_{1}\left(x_{1}(t), t, s\right)} e^{\mu_{5}(s-t)} \frac{m\left(s-t_{0}\right)}{m\left(t-t_{0}\right)},
$$

where the participant begins employment at time $t_{0}$ and $m\left(t-t_{0}\right)$ represents the merit component of wage growth, which is a function of length of service $(t-t)$.

The "best estimate" working consumption at time $s$ is:

$$
\begin{aligned}
\varepsilon_{t}(C(s)) & =\varepsilon_{t}((1-\pi) Y(s)) \\
& =(1-\pi) Y(s) \frac{P_{3}\left(x_{3}(t), t, s\right)}{P_{1}\left(x_{1}(t), t, s\right)} e^{\mu_{5}(s-t)} \frac{m\left(s-t_{0}\right)}{m\left(t-t_{0}\right)}
\end{aligned}
$$

The "best estimate" future retirement consumption, $\varepsilon_{t}\left(C^{R}(R)\right)$, is the anticipated pension purchasable at time $R\left(=\varepsilon_{t}\left(P W(R) / \ddot{a}_{x+R-t}(R)\right)\right)$. Since we determine each element of the "best estimate" value by parts, we can write it as:

$$
\varepsilon_{t}\left(C^{R}(R)\right)=\frac{\varepsilon_{t}(P W(R))}{\varepsilon_{t}\left(\ddot{a}_{x+R-t}(R)\right)} .
$$

In the numerator, the pension wealth accumulates with investment returns and contributions. Assuming the worker projects future investment returns using the return on zero-coupon bonds with a maturity date that corresponds to the contemplated date of retirement, we calculate the projected pension income at retirement with:

$$
\varepsilon_{t}(P W(R))=\left(P W(t)+\pi Y(t) \ddot{a} \frac{x_{3,5}(t)}{R-t \mid}\right) / P_{1}\left(x_{1}(t), t, R\right)
$$

and we calculate the projected annuity at retirement with:

$$
\varepsilon_{t}\left(\ddot{a}_{x+R-t}(R)\right)=\ddot{a}_{x+R-t}^{x_{1}(t)}(R)=\sum_{s=R}^{\infty} P_{1}\left(x_{1}(t), R, s\right)_{s-R} \mathrm{p}_{x+R-t},
$$

where the superscript $x_{1}(t)$ in $\ddot{a}_{x+R-t}^{x_{1}(t)}(R)$ signifies that $\ddot{a}_{x+R-t}(R)$ is computed using the current nominal risk-free rate of interest, $x_{1}(t)$, and the resulting yield curve. Likewise, $\ddot{a}_{R-t}^{x_{3,5}(t)}$ is the value of an annuity certain factor with the anticipated earnings scale based on information at time $t$. Relying on the risk-free real interest rate $\left(x_{3}(t)\right)$, the long-term real wage growth $\left(\mu_{5}\right)$ and the merit component $\left(m\left(t-t_{0}\right)\right), \ddot{a} \frac{x_{3,5}(t)}{R-t} \mid$ is given by:

$$
\ddot{a} \frac{x_{3,5}(t)}{R-t}=\sum_{s=t}^{\infty} \frac{\varepsilon_{t}(Y(s))}{Y(t)} P_{1}\left(x_{1}(t), t, s\right)=\sum_{s=t}^{R-t-1} P_{3}\left(x_{3}(t), t, s\right) e^{\mu_{5}(s-t)} \frac{m\left(s-t_{0}\right)}{m\left(t-t_{0}\right)} .
$$


Dividing the expected consumption by the current earnings in Eqs. (20) and (21), we get:

$$
\frac{\varepsilon_{t}(C(s))}{Y(t)}=(1-\pi) \frac{P_{3}\left(x_{3}(t), t, s\right)}{P_{1}\left(x_{1}(t), t, s\right)} e^{\mu_{5}(s-t)} \frac{m\left(s-t_{0}\right)}{m\left(t-t_{0}\right)}
$$

and

$$
\frac{\varepsilon_{t}\left(C^{R}(R)\right)}{Y(t)}=\frac{\left(R R(t) \ddot{a}_{x}(t)+\pi \ddot{a}_{\overline{3,5}}^{x_{3, t}(t)}\right)}{P_{1}\left(x_{1}(t), t, R\right)} / \ddot{a}_{x+R-t}^{x_{1}(t)}(R),
$$

since since $C^{t}(t) / Y(t)=P W(t) / \ddot{a}_{x}(t)=R R(t)$ and $C(t) / Y(t)=1-\pi$.

Using the anticipated consumption projections from Eqs. (23) and (24), we are now in a position to express Eq. (18) as an function of the current replacement ratio.

$$
\begin{aligned}
& E_{t}\left(V^{R}(t)\right)-E_{t}\left(V^{t}(t)\right) \\
\approx & \sum_{s=t}^{R-1} \beta^{s-t}{ }_{s-t} \mathrm{p}_{x}\left[(1-\pi) \frac{P_{3}\left(x_{3}(t), t, s\right)}{P_{1}\left(x_{1}(t), t, s\right)} e^{\mu_{5}(s-t)} \frac{m\left(s-t_{0}\right)}{m\left(t-t_{0}\right)}\right]^{\gamma} \\
& +\sum_{s=R}^{\infty} \beta^{s-t}{ }_{s-t} \mathrm{p}_{x} k^{\gamma}\left[\frac{\left(R R(t) \ddot{a}_{x}(t)+\pi \ddot{a}_{\overline{3}, 5}(t)\right.}{P_{1}\left(x_{1}(t), t, R\right)} / \ddot{a}_{x+R-t}^{x_{1}(t)}(R)\right]^{\gamma} \\
& -\sum_{s=t}^{\infty} \beta^{s-t}{ }_{s-t} \mathrm{p}_{x} k^{\gamma} R R(t)^{\gamma}+\sum_{s=t}^{R-1} \beta^{s-t}{ }_{s-t} \mathrm{p}_{x} v(t) .
\end{aligned}
$$

Retirement occurs when Eq. (25) $\leq 0$ for all $R$ :

$$
E_{t}\left(V^{t}(t)\right) \geq E_{t}\left(V^{R}(t)\right) \forall R \geq t
$$

\section{B.2 One-Year Model}

If we move the OY model's Eq. (14) from full expectation to a single "best estimate" of the future then, incorporating Appendix B.1's solutions for $\varepsilon_{t}(C(s)), \varepsilon_{t}\left(C^{R}(R)\right)$ and $\varepsilon_{t}\left(\ddot{a}_{x+R-t}(R)\right)$, it becomes a function of $R R(t)$ :

$$
\begin{aligned}
E_{t}\left(V^{t+1}(t)\right)-E_{t}\left(V^{t}(t)\right) \approx & (1-\pi)^{\gamma}+\sum_{s=t+1}^{\infty} \beta^{s-t}{ }_{s-t} \mathrm{p}_{x} k^{\gamma} \\
& \times\left(\frac{R R(t) \ddot{a}_{x}(t)+\pi}{P_{1}\left(x_{1}(t), t, t+1\right) \ddot{a}_{x+1}^{x_{1}(t)}(t+1)}\right)^{\gamma}+\beta_{1} \mathrm{p}_{x} \mathrm{~L} \\
& -\sum_{s=t}^{\infty} \beta^{s-t}{ }_{s-t} \mathrm{p}_{x}(k R R(t))^{\gamma}-\mathrm{L}+v(t)
\end{aligned}
$$

Retirement occurs when Eq. (27) $\leq 0$; that is:

$$
E_{t}\left(V^{t}(t)\right) \geq E_{t}\left(V^{t+1}(t)\right)
$$

